\title{
Comparison of metformin and insulin versus insulin alone for type 2 diabetes: systematic review of randomised clinical trials with meta-analyses and trial sequential analyses
}

\author{
(c) $)$ (1) \& 8 OPEN ACCESS
}

Bianca Hemmingsen $P h D$ student ${ }^{1}$, Louise Lundby Christensen physician ${ }^{2}$, Jørn Wetterslev chief physician ${ }^{1}$, Allan Vaag professor ${ }^{3}$, Christian Gluud chief physician and head of department ${ }^{1}$, Søren S Lund physician ${ }^{4}$, Thomas Almdal chief physician and head of department ${ }^{4}$

${ }^{1}$ Copenhagen Trial Unit, Centre for Clinical Intervention Research, Rigshospitalet, Copenhagen University Hospital, DK-2100 Copenhagen, Denmark; ${ }^{2}$ Department of Paediatrics, Hvidovre University Hospital, Hvidovre, Denmark; ${ }^{3}$ Department of Endocrinology, Rigshospitalet, Copenhagen University Hospital; ${ }^{4}$ Steno Diabetes Centre, Gentofte, Denmark

\begin{abstract}
Objectives To compare the benefits and harms of metformin and insulin versus insulin alone as reported in randomised clinical trials of patients with type 2 diabetes.

Design Systematic review of randomised clinical trials with meta-analyses and trial sequential analyses.

Data sources The Cochrane Library, Medline, Embase, Science Citation Index Expanded, Latin American Caribbean Health Sciences Literature, and Cumulative Index to Nursing and Allied Health Literature until March 2011. We also searched abstracts presented at the American Diabetes Association and European Association for the Study of Diabetes Congresses, contacted relevant trial authors and pharmaceutical companies, hand searched reference lists of included trials, and searched the US Food and Drug Administration website.

Review methods Two authors independently screened titles and abstracts for randomised clinical trials comparing metformin and insulin versus insulin alone (with or without placebo) in patients with type 2 diabetes, older than 18 years, and with an intervention period of at least 12 weeks. We included trials irrespective of language, publication status, predefined outcomes, antidiabetic interventions used before randomisation, and reported outcomes.

Results We included 26 randomised trials with 2286 participants, of which 23 trials with 2117 participants could provide data. All trials had high risk of bias. Data were sparse for outcomes relevant to patients. Metformin and insulin versus insulin alone did not significantly affect all cause mortality (relative risk $1.30,95 \%$ confidence interval 0.57 to 2.99 ) or cardiovascular mortality $(1.70,0.35$ to 8.30$)$. Trial sequential analyses
\end{abstract}

showed that more trials were needed before reliable conclusions could be drawn regarding these outcomes. In a fixed effect model, but not in a random effects model, severe hypoglycaemia was significantly more frequent with metformin and insulin than with insulin alone $(2.83,1.17$ to 6.86). In a random effects model, metformin and insulin resulted in reduced $\mathrm{HbA}_{10}$, weight gain, and insulin dose, compared with insulin alone; trial sequential analyses showed sufficient evidence for a $\mathrm{HbA}_{1 \mathrm{c}}$ reduction of $0.5 \%$, lower weight gain of $1 \mathrm{~kg}$, and lower insulin dose of 5 U/day.

Conclusions There was no evidence or even a trend towards improved all cause mortality or cardiovascular mortality with metformin and insulin, compared with insulin alone in type 2 diabetes. Data were limited by the severe lack of data reported by trials for patient relevant outcomes and by poor bias control.

\section{Introduction}

Metformin is a glucose lowering drug that, among other mechanisms, is supposed to work by enhancing insulin action mainly in the liver. ${ }^{1}$ Metformin is often recommended as the first line drug in patients with type 2 diabetes. ${ }^{2}$ Because of disease progression, a substantial proportion of these patients eventually end up on insulin, at which point doctors are recommended to continue metformin use. ${ }^{2}$ The rationale behind this combination mainly relates to suggested beneficial metabolic effects, such as reduced blood glucose and body weight. ${ }^{2-4}$ 
The United Kingdom Prospective Diabetes Study suggested a beneficial effect of metformin monotherapy, compared with conventional (diet) treatment, on cardiovascular disease and mortality after about 10 years in overweight patients with type 2 diabetes. ${ }^{5}$ These findings were partly supported by the Hyperinsulinemia: the Outcome of its Metabolic Effects (HOME) trial comparing combined metformin and insulin versus insulin alone. ${ }^{6}$ However, other trials have suggested that metformin combined with sulphonylurea (that is, insulin secretagogues) versus sulphonylurea alone could increase mortality. ${ }^{57}$ Thus, the effect of metformin combined with other glucose lowering drugs such as insulin providing regimens on patient relevant outcomes might differ from its effects during monotherapy.

Whether oral glucose lowering drugs should be continued when initiating insulin remains unclear. ${ }^{89}$ An insulin sparing effect has been observed when using oral glucose lowering drugs with insulin. ${ }^{9}$ However, the progressive nature of type 2 diabetes with its decline in endogenous insulin secretion could result in patients with advanced disease more closely resembling type 1 diabetes, in which adjunct treatment with, for example, metformin, has not proven to improve glycaemic control. ${ }^{10}$ Thus, despite international recommendations to use metformin in combination with insulin in patients with type 2 diabetes and therefore the possible widespread use of this treatment regimen worldwide, insufficient and contradictory data exist in the literature to justify this policy. ${ }^{2}$

Previous meta-analyses of glucose lowering drugs have included trials of insulin in combination with various glucose lowering compounds such as metformin, but have not addressed the specific effect of metformin and insulin in this respect. ${ }^{11-13}$ In the light of these considerations and the growing number of patients with type 2 diabetes receiving insulin worldwide, we compared the benefits and harms of metformin and insulin versus insulin alone in randomised clinical trials.

\section{Methods}

The present review followed the Cochrane Collaboration's recommendations for preparation of systematic reviews of interventions ${ }^{14}$ and was based on a previously published protocol. $^{15}$

\section{Search strategy}

We searched the Cochrane Library, Medline, Embase, Science Citation Index Expanded, Latin American Caribbean Health Sciences Literature, and Cumulative Index to Nursing and Allied Health Literature until March 2011 (web appendix). We also searched abstracts presented at the American Diabetes Association and European Association for the Study of Diabetes Congresses. We contacted relevant pharmaceutical companies, and searched the US Food and Drug Administration website for unpublished randomised trials relevant to the review. We also scanned reference lists of included trials and systematic reviews, meta-analyses, and health technology assessment reports. We contacted experts to request for information on additional trials.

\section{Study selection}

Two authors (BH and LLC or TA) independently screened titles and abstracts according to the inclusion criteria. Randomised clinical trials were included if they compared metformin and insulin versus insulin alone (with or without placebo) in patients with type 2 diabetes older than 18 years, and had an intervention period of at least 12 weeks. We included trials irrespective of language, publication status, predefined outcomes, antidiabetic interventions used before randomisation, and reported outcomes. We excluded intervention groups including concomitant use of glucose lowering drugs other than metformin or insulin.

\section{Data extraction and risk of bias assessment}

Two authors (BH and LLC or TA) independently extracted data from the included trials using standard forms, and assessed the risk of bias according to the Cochrane Collaboration. ${ }^{14}$ They assessed the following risk of bias domains: generation of the allocation sequence, allocation concealment, blinding of investigators and participants, blinding of outcome assessors, incomplete outcome data, selective outcome reporting, and other sources of bias. ${ }^{15}$ Each item was classified as low, unclear, or high risk of bias. ${ }^{15}$ The involvement of a third author (JW or CG) resolved any discrepancies. Data extraction and assessment for all relevant non-English articles were obtained through translated texts.

The primary outcomes in this review were all cause mortality and cardiovascular mortality. ${ }^{15}$ The secondary outcomes were macrovascular and microvascular diseases assessed as composite outcomes and in separate (non-fatal myocardial infarction, non-fatal stroke, abdominal aorta aneurism, amputation of lower extremity, cardial or peripheral revascularisation, manifestation and progression of nephropathy, end stage renal disease, manifestation and progression of retinopathy, or retinal photocoagulation) adverse events, cancer, quality of life, costs of intervention, insulin dose, glycaemic control, weight, and blood pressure. $^{15}$

\section{Statistical analysis}

We did statistical analysis using Review Manager ${ }^{16}$ according to our protocol. ${ }^{15}$ The medians reported in the included trials were assumed to be close to the arithmetic mean. If not reported, the standard deviation of the changes from baseline to the end of follow-up was calculated with a correlation coefficient from the largest and longest trial with all available data for each continuous variable in each intervention group. ${ }^{14-18}$ Reported standard errors and confidence intervals were converted to standard deviations.

We used both a random effects model and a fixed effect model. ${ }^{19}{ }^{20}$ In case of discrepancy between the two models, we reported both results. We examined heterogeneity with the $\mathrm{I}^{2}$ statistic ( $\mathrm{I}^{2} \geq 50 \%$ indicated substantial heterogeneity). ${ }^{14}$ To clarify the influence of missing data, we conducted scenario analyses for the "worst best" case and "best worst" case for the primary outcomes.

We did subgroup analyses for primary and secondary outcomes if significant effect estimates were present using a test of interaction. These analyses were done according to risk of bias (low $v$ high risk), study design (blinding $v$ no blinding of participants and investigators), previous insulin treatment (insulin naive $v$ previous insulin treatment), insulin regimen (fixed $v$ variable regimens in intervention groups), body mass index at baseline $(<30 v \geq 30)$, duration of interventions ( $<$ two years $v \geq$ two years), metformin use at trial entry (allowed $v$ not allowed), and publication status (published $v$ unpublished trials).

\section{Trial sequential analysis}

Trial sequential analysis of a meta-analysis is conceptually similar to interim analyses in a single trial, which use monitoring boundaries to decide whether the trial has obtained a sufficiently low $\mathrm{P}$ value to show a reliable effect. ${ }^{21-25}$ Cumulative 
meta-analyses of trials are at risk of producing random errors because of sparse data and repetitive testing on accumulating data. ${ }^{23-27}$ Trial sequential analysis depends on the quantification of the required information size. ${ }^{25}$

The trial sequential analysis was done to maintain an overall $5 \%$ risk of a type I error and $20 \%$ of the type II error. On the basis of criteria decided a priori, we calculated the required information size (adjusted for diversity) to detect or reject an intervention effect of a $10 \%$ relative risk reduction, considered as a clinically relevant effect corresponding to a numbers needed to treat of about $200 .{ }^{21-28}$ However, if the required information size was very large, we also performed post hoc trial sequential analysis, with a $30 \%$ relative risk reduction. For the continuous outcomes of glycated haemoglobin $\left(\mathrm{HbA}_{1 \mathrm{c}}\right)$, weight gain, and insulin dose, we estimated the required information sizes to detect or reject a reduction of $0.5 \%, 1 \mathrm{~kg}$, and $5 \mathrm{U} /$ day, respectively. We used software Trial Sequential Analysis, version $0.8 .^{27}$

\section{Differences between planned protocol and review}

The subgroup analysis conducted on the secondary outcomes showing significance was not defined in our protocol. ${ }^{15}$ The subgroup analyses for insulin regimen (fixed $v$ variable) as well as metformin use at trial entry (allowed $v$ not allowed) were not described in our protocol. ${ }^{15} \mathrm{We}$ did not do subgroup analyses for mean age younger than 65 years compared with 65 years or older and for insulin type prescribed. We extracted data but did not report data for cancer, fasting blood glucose, and blood pressure. When the estimated required information size (to show or refute a $10 \%$ relative risk reduction) was very large, we did a trial sequential analysis for a $30 \%$ relative risk reduction. The estimated required information sizes based on small anticipated reductions in the surrogate outcomes of $\mathrm{HbA}_{1 \mathrm{c}}$, weight gain, and insulin dose of $0.5 \%, 1 \mathrm{~kg}$, and $5 \mathrm{U} /$ day, respectively, were chosen post hoc to substantially challenge the effect on these outcomes, in view of sparse data and repetitive testing.

\section{Results}

\section{Results of the search and trial, participant, and intervention characteristics}

We identified 7993 references through electronic and hand searches (fig $1 \Downarrow$ ). After excluding the duplicate reports, we screened 5613 references. Most references did not identify relevant trial reports. Thirty publications describing 26 randomised clinical trials met our inclusion criteria, randomly assigning 2286 patients to metformin and insulin versus to insulin alone. Three trials could not provide data for the meta-analysis because they only described the total number of patients who underwent randomisation. ${ }^{29}{ }^{30}$ Accordingly, 23 trials (2117 participants) provided data for our analyses. Schnack and colleagues did not report the total number of randomised patients, but only the number with available data at the time of publication of the abstract. ${ }^{31}$

Twenty five trials were published in English and one in Russian. One trial was only published as abstracts, ${ }^{29-33}$ one in a single abstract, ${ }^{31}$ and one in a letter. ${ }^{34}$ All trial authors were contacted, but only a few provided additional data. We included two crossover trials, and the authors were unable to provide data before the crossover. ${ }^{30}{ }^{35}$ Tables 1 and $2 \Downarrow \Downarrow$ show baseline characteristics of the included trials.

Twelve trials included insulin naive participants (table $3 \Downarrow$ )..$^{3-43}$ Fifteen trials allowed metformin at trial entry either as monotherapy or in combination with other antidiabetic drugs (table 3). ${ }^{4.46}$ We were unable to retrieve information about the duration of metformin intervention before randomisation. The total daily dose of metformin in the intervention groups varied between $1000 \mathrm{mg}$ and $2550 \mathrm{mg}$. Insulin regimens differed between the trials, and also varied between the intervention groups within some trials (table 3 ) ${ }^{3-47}$ Three trials prescribed a fixed and identical insulin regimen in both intervention groups. ${ }^{48-50}$

Altuntas and colleagues reported three intervention groups: insulin lispro and metformin, insulin lispro and neutral protamine Hagedorn insulin, and human regular insulin and neutral protamine Hagedorn insulin. ${ }^{43}$ In our analysis, we merged the data from the two insulin only groups into one dataset. ${ }^{43}$ The South Danish Diabetes Study reported two different kinds of insulin treatments (neutral protamine Hagedorn insulin and insulin aspart) in combination with different oral antidiabetic drugs. For this study, ${ }^{44}$ we reported the two types of insulin preparations in combination with metformin or placebo separately: neutral protamine Hagedorn insulin in combination with metformin or placebo (SDDSa), and insulin aspart in combination with metformin or placebo (SDDSb).

\section{Bias risk assessment}

Five trials had low risk of bias regarding both sequence generation and allocation concealment (table $4 \Downarrow$ ). ${ }^{6-47}$ Healthcare providers and participants were blinded in 10 trials, ${ }^{4-50}$ and not blinded in $16^{3-51}$ Only two trials ${ }^{644}$ described adequate sequence generation, allocation concealment, and blinding of participants and investigators, which our protocol had prespecified as trials with lower risk of bias. ${ }^{15}$ The trials did not report the funding source, or report funding from the pharmaceutical industry. Based on all the domains assessed, none of the included trials had a low risk of bias.

\section{All cause mortality}

Sixteen trials with 1627 participants reported all cause mortality, of which five reported 21 deaths (fig $2 \Downarrow$ ). Metformin and insulin versus insulin alone did not significantly affect all cause mortality (relative risk $1.30,95 \%$ confidence interval 0.57 to 2.99; heterogeneity $\mathrm{I}^{2}=0 \%, \mathrm{P}=0.77$ ). Trial sequential analysis indicated that only $2.93 \%$ of the required information size was accrued to detect or reject a $30 \%$ reduction in relative risk.

The "best worst" case scenario for all cause mortality showed a significant difference in favour of metformin combined with insulin (relative risk $0.35,95 \%$ confidence interval 0.13 to 0.95 , $\mathrm{P}=0.04)$. However, the "worst best" case scenario showed a significant effect favouring insulin alone $(4.27,1.74$ to 10.45 , $\mathrm{P}=0.001)$. Test of interaction for subgroup differences did not show any significance regarding bias $(\mathrm{P}=0.90)$, blinding of investigators and participants $(\mathrm{P}=0.90)$, duration of interventions $(\mathrm{P}=0.90)$, body mass index $(\mathrm{P}=0.83)$, previous insulin treatment $(\mathrm{P}=0.89)$, or metformin use allowed at trial entry $(\mathrm{P}=0.56)$.

Subgroup analysis according to insulin regimen used was not possible because the three trials with fixed insulin regimens in intervention groups reported no fatal events. ${ }^{48-50} \mathrm{We}$ also could not analyse publication status because all the included trials were published. A separate analysis of the trials using placebo control groups (the HOME trial ${ }^{6}$ and South Danish Diabetes Study ${ }^{44}$ ) did not show any significant effect of metformin and insulin (relative risk $1.27,95 \%$ confidence interval 0.50 to 3.22 ).

\section{Cardiovascular mortality}

Fifteen trials with 1498 participants reported on cardiovascular mortality, of which three trials reported six deaths (fig 2). The 
effect of metformin and insulin versus insulin alone was non-significant (relative risk $1.70,95 \%$ confidence interval 0.35 to 8.30 ; heterogeneity $\mathrm{I}^{2}=0 \%, \mathrm{P}=0.52$ ). Trial sequential analysis indicated that only $0.65 \%$ of the required information size was accrued to detect or reject a $30 \%$ reduction in relative risk.

The "best worst" case scenario showed significant benefit for metformin and insulin compared with insulin alone (relative risk $0.25,95 \%$ confidence interval 0.09 to $0.73, \mathrm{P}=0.01$ ). The "worst best" case scenario showed significant harm for metformin and insulin $(7.45,3.08$ to $18.03, \mathrm{P}<0.001)$. Test of interaction for subgroup differences did not show any significance regarding bias $(\mathrm{P}=0.48)$, blinding of investigators and participants $(\mathrm{P}=0.50)$, duration of intervention $(\mathrm{P}=0.50)$, body mass index $(\mathrm{P}=0.25)$, previous insulin treatment $(\mathrm{P}=0.99)$, or metformin use allowed at trial entry $(\mathrm{P}=0.51)$. The HOME trial was the only placebo controlled trial to report any deaths due to cardiovascular disease. ${ }^{6}$ We could not analyse the insulin regimen used because the three trials with fixed insulin regimens reported no fatal events. ${ }^{48-50} \mathrm{We}$ also could not analyse publication status because all the included trials were published.

\section{Macrovascular and microvascular complications}

The reporting of macrovascular and microvascular complications was infrequent, and all the outcomes assessed showed non-significant effect estimates (data not shown). We also observed a non-significant effect for the composite macrovascular outcome (relative risk $0.98,0.79$ to 1.22 ; heterogeneity $\mathrm{I}^{2}=0, \mathrm{P}=0.44$; three trials). Only one trial reported data for the composite microvascular outcome, and showed no significant effect of metformin and insulin versus insulin alone. ${ }^{6}$

\section{Hypoglycaemia}

Most trials reported hypoglycaemia data in a format that could not be included in a meta-analysis. ${ }^{3-48}$ Eleven trials with 1303 participants reported severe hypoglycaemia (fig $3 \Downarrow$ ). Only three trials reported severe hypoglycaemia in 24 patients (metformin and insulin, 18; placebo and insulin, six). The remaining eight trials reported no serious hypoglycaemic events. Although the random effects model did not show a significant effect (relative risk $2.43,95 \%$ confidence interval 0.54 to 10.85 ), the fixed effects model did $\left(2.83,1.17\right.$ to 6.86 ; heterogeneity $\mathrm{I}^{2}=43 \%$, $\mathrm{P}=0.17$ ), suggesting that metformin and insulin was associated with an increased number of patients with severe

hypoglycaemia. Separate analysis of the two trials providing data for severe hypoglycaemia using placebo did not show a significant effect in the random effects model (3.59, 0.75 to 17.33), but showed significance in favour of insulin alone in the fixed effects model $(3.56,1.34$ to $9.48, \mathrm{P}=0.01)$.

As the largest and longest trial, the HOME trial did not report the number of participants with serious hypoglycaemia at the end of the intervention period. However, after 4.3 years of treatment, researchers saw no significant difference in severe hypoglycaemia between intervention groups $(0.3$ severe hypoglycaemic events per person per year, for each group). ${ }^{6}$

We extracted data for mild hypoglycaemia from six trials (869 participants; fig 3), which showed no significant effect of metformin and insulin versus insulin alone (relative risk 1.01, $95 \%$ confidence interval 0.85 to 1.20 ; heterogeneity $\mathrm{I}^{2}=27 \%$, $\mathrm{P}=0.23)$. Meta-analysis of the trials applying placebo did not substantially change this estimate $(0.97,0.83$ to 1.14$)$.

\section{Adverse events}

Only six trials reported adverse events, and showed no significant difference between intervention groups (relative risk $1.28,95 \%$ confidence interval 0.69 to 2.37 ; heterogeneity $\left.\mathrm{I}^{2}=75 \%, \mathrm{P}=0.003\right)$. Hermann and colleagues conducted the only placebo controlled trial reporting adverse events, and did not find any significant difference in effect between the interventions. ${ }^{50}$ The effect of dropouts owing to adverse events was close to significance in the random effects model when comparing metformin and insulin versus insulin alone (1.53, 0.99 to $2.36, \mathrm{P}=0.05)$; this effect and was significant in the fixed effect model $\left(1.69,1.13\right.$ to $2.52, \mathrm{P}=0.01$; heterogeneity $\mathrm{I}^{2}=1 \%$, $\mathrm{P}=0.43)$. Meta-analysis of the trials using placebo did not substantially change the estimate (1.41, 0.72 to 2.76$)$.

Six trials reported four serious adverse events. The definition of serious adverse events varied among trials. The effect estimate was non-significant (relative risk 1.92, 0.33 to 11.35; heterogeneity $\mathrm{I}^{2}=0 \%, \mathrm{P}=0.43$ ). Hermann and colleagues conducted the only placebo controlled trial reporting any serious adverse events, and did not show any significant difference between the interventions. ${ }^{50}$

\section{Quality of life}

Three trials reported quality of life or wellbeing; all found no significant differences regarding these outcomes. ${ }^{4-41}$ Only Douek and colleagues reported quality of life assessments in a format that was suitable for a meta-analysis. ${ }^{4}$

\section{Insulin dose}

Twelve trials reported changes in insulin dose (fig $4 \Downarrow$ ). Insulin dose was significantly reduced when metformin was combined with insulin, compared with insulin alone (mean difference $-18.65 \mathrm{U} /$ day, $95 \%$ confidence interval -22.70 to -14.60 , $\mathrm{P}<0.001$; heterogeneity $\left.\mathrm{I}^{2}=81 \%, \mathrm{P}<0.001\right)$. Trial sequential analysis showed that sufficient evidence was established to show even a small reduction of $5 \mathrm{U} /$ day, with crossing of the trial sequential alpha spending monitoring boundary (fig $5 \Downarrow$ ).

Subgroup analysis of the trials according to risk of bias did not show any significant differences in the effect estimate for insulin dose $(\mathrm{P}=0.19$, test of interaction). Separate analysis of trials using placebo according to blinding of participants and investigators suggested a more pronounced reduction of insulin use (mean difference $-21.01 \mathrm{U} /$ day, $95 \%$ confidence interval -23.88 to $-18.15, \mathrm{P}<0.001)$ compared with trials not using placebos (open label design) ( $-16.78 \mathrm{U} /$ day, -22.07 to -11.49 , $\mathrm{P}<0.001)$. However, tests of interaction did not show any significant differences between subgroups in relation to the blinding of investigators and participants $(\mathrm{P}=0.17)$, previous insulin treatment $(\mathrm{P}=0.15)$, insulin regimen $(\mathrm{P}=0.67)$, and duration of intervention $(\mathrm{P}=0.19$; although only one trial with a duration of intervention of two years or more was included in the analysis). ${ }^{6}$ Trials with participants who had a body mass index of less than 30 at baseline showed a smaller reduction in daily insulin dose $(-13.36 \mathrm{U} / \mathrm{day},-18.52$ to $-8.20, \mathrm{P}<0.001)$ than those with participants who had a body mass index of 30 or more $(-21.76 \mathrm{U} /$ day, -26.99 to $-16.53, \mathrm{P}<0.001)$. Test of interaction showed significance for the subgroup differences according to body mass index $(\mathrm{P}=0.03)$, but not significant according to metformin use at trial entry $(\mathrm{P}=0.88)$. Subgroup analysis of publication status was not possible. 


\section{Glycaemic control}

Twenty trials reported changes in $\mathrm{HbA}_{1 \mathrm{c}}$. The achieved percentage of $\mathrm{HbA}_{1 \mathrm{c}}$ decreased with metformin and insulin compared with insulin alone (mean difference $-0.60 \%, 95 \%$ confidence interval -0.89 to $-0.31, \mathrm{P}<0.001 ; 20$ trials; heterogeneity $\mathrm{I}^{2}=82 \%, \mathrm{P}<0.001$ ) (fig $6 \Downarrow$ ). Standard deviations of the changes had to be calculated for most trials. Trial sequential analysis showed that sufficient evidence was available to show a reduction of $0.5 \%$ in $\mathrm{HbA}_{1 \mathrm{c}}$, with crossing of the trial sequential monitoring boundary in favour of metformin and insulin (fig 5).

A test of interaction found no significant subgroup difference between the two trials with lower risk of bias and the remaining trials with high risk of bias $(\mathrm{P}=0.81)$. Trials designed to blind participants and investigators showed a reduction in $\mathrm{HbA}_{\mathrm{lc}}$ (mean difference $-0.87 \%, 95 \%$ confidence interval -1.30 to $-0.44, \mathrm{P}<0.001)$ greater than that observed in trials without blinding $(-0.30 \%,-0.62$ to $0.01 ; \mathrm{P}=0.06$, test of interaction). Tests of interactions did not show significant subgroup differences according to previous insulin treatment $(\mathrm{P}=0.18)$, body mass index $(\mathrm{P}=0.07)$, and duration of intervention $(\mathrm{P}=0.72)$. Trials with variable insulin regimens in the intervention groups showed a smaller reduction in $\mathrm{HbA}_{1 \mathrm{c}}$ $(-0.46 \%,-0.72$ to $-0.20, \mathrm{P}<0.001)$ than trials with fixed insulin regimens $(-1.44 \%,-1.72$ to $-1.17, \mathrm{P}<0.001 ; \mathrm{P}<0.001$, test of interaction). Subgroup analyses of metformin use at trial entry did not show any significant effect $(\mathrm{P}=0.38$, test of interaction). Subgroup analysis of publication status was not possible.

\section{Weight}

Both body mass index and weight gain were significantly reduced by metformin and insulin compared with insulin alone (body mass index, mean difference $-1.27,95 \%$ confidence interval -2.07 to $-0.47, \mathrm{P}=0.002$, six trials (heterogeneity $\left.\mathrm{I}^{2}=86 \%, \mathrm{P}<0.001\right)$; weight gain, $-1.68 \mathrm{~kg},-2.22$ to -1.13 , $\mathrm{P}<0.001,13$ trials $\left(\mathrm{I}^{2}=36 \%, \mathrm{P}=0.09\right)$ ) (fig $7 \Downarrow$ ). Trial sequential analysis showed that sufficient evidence was available to show a reduction of $1 \mathrm{~kg}$ in weight, with crossing of the trial sequential monitoring boundary for less weight gain with metformin and insulin than insulin alone (fig 5).

Tests of interaction of weight changes did not find any significant subgroup differences according to risk of bias $(\mathrm{P}=0.33)$, previous insulin treatment $(\mathrm{P}=0.27)$, or blinding of investigators and participants $(\mathrm{P}=0.45)$, or insulin regimen $(\mathrm{P}=0.51)$. The change in weight for trials using placebo was significant (mean difference $-1.97 \mathrm{~kg}, 95 \%$ confidence interval -2.59 to $-1.35, \mathrm{P}<0.001)$. Separate analysis of trials with a duration of intervention of two years or longer showed a weight loss $(-2.07 \mathrm{~kg},-2.22$ to $-1.13, \mathrm{P}<0.001)$. Tests of interactions for subgroup differences did not show any significance according to trial duration $(\mathrm{P}=0.33)$ or body mass index $(\mathrm{P}=0.62)$. Trials allowing participants to receive metformin at entry showed a less pronounced weight loss $(-1.79 \mathrm{~kg},-2.40$ to $-1.18, \mathrm{P}<0.001)$ than trials not allowing metformin use $(-2.93$ $\mathrm{kg},-4.13$ to $-1.74, \mathrm{P}<0.001 ; \mathrm{P}=0.03$, test of interaction). Subgroup analysis of publication status was not possible.

\section{Discussion}

We identified 26 randomised clinical trials comparing the effects of metformin and insulin with insulin alone. Of these trials, 23 $(n=2117$ participants) provided sufficient information to be included in one or more meta-analyses. All trials had a high risk of bias, and only two were considered to have lower risk of bias. This finding could lead to a systematic overestimation of beneficial effects and an underestimation of adverse effects. ${ }^{52-55}$ Nevertheless, metformin combined with insulin seem to be associated with a significant reduction in $\mathrm{HbA}_{1 c}$, weight gain, and insulin dose, compared with insulin alone. Although the influence of bias cannot be excluded, trial sequential analysis suggested evidence was sufficient for the effect, found in a random effects model, of metformin and insulin versus insulin alone on these surrogate outcomes. However, duration of intervention in the included trials was relatively short, and we were unable to explore whether these metabolic effects disappear, persist, or became more pronounced with time. Meta-analyses of patient relevant outcomes were based on very sparse data and did not show significant results. The accrued cumulated sample sizes of the included trials for the primary outcomes only constituted a very small fraction of the required information size calculated to establish firm evidence for the presence or absence of effect.

The present systematic review contains substantially more data than previous meta-analyses relevant to the topic. ${ }^{11}{ }^{12}$ Although our results seem to support the combination of metformin and insulin compared with insulin alone on $\mathrm{HbA}_{1 \mathrm{c}}$, weight, and insulin dose, these variables are, at best, unvalidated surrogate indicators of a potentially reduced risk of microvascular and macrovascular complications.$^{56}$ Our results regarding patient relevant outcomes should be interpreted with caution. Several of these outcomes were rarely reported or not reported at all. Major drawbacks of the meta-analyses of patient relevant outcomes mirrored the weaknesses of the included trials, and highlighted the substantial lack of evidence on this topic. Most trials had a short duration (<two years) and we cannot exclude a potential legacy effect from the trials allowing metformin at baseline. However, we were unable to show any legacy effect apart from one on weight loss. These factors might have diluted a potential effect of metformin and insulin in two trials in the meta-analysis with a longer duration.

After combining all the evidence available from randomised clinical trials, we were unable to find any evidence or even a trend towards improved all cause mortality or cardiovascular mortality with metformin and insulin, compared with insulin alone. Point estimates of the risk ratios for all cause or cardiovascular mortality were greater than one (that is, favouring insulin alone); these risk ratios or the upper limits of their $95 \%$ confidence intervals spanned far beyond current safety limits such as 1.3 or 1.8 , as used for evaluating drug safety by the US Food and Drug Administration. ${ }^{57}$ This lack of evidence means that possible harm cannot be excluded according to current criteria. However, several factors limited the confidence in the effect estimates and confidence intervals in our meta-analyses, owing to insufficient information and consequent high risk of random errors.

The risk of having one or more severe hypoglycaemic events was significantly increased with metformin and insulin when applying the fixed effect model. The combination of metformin and insulin seemed to decrease $\mathrm{HbA}_{1 \mathrm{c}}$, which might have explained the observed tendency of an increased risk of severe hypoglycaemia. ${ }^{58}{ }^{59}$ Furthermore, the largest and longest of the included trials, the HOME trial, did not find any difference in the number of severe hypoglycaemic events per person per year, implying that the observed potential harm might not be present during a longer intervention period. ${ }^{6} \mathrm{We}$ did not adjust the number of patients who had severe hypoglycaemia with the achieved $\mathrm{HbA}_{1 \mathrm{c}}$ in trials. Since both the achieved glycaemic level and the number of hypoglycaemic events are results of the interventions, it is not possible in real life to have only one outcome without the other. Thus, any conclusions from 
statistically adjusting the risk of hypoglycaemia for results of achieved glycaemic control cannot be translated into clinical practice. Therefore, a possible signal of harm, when combining metformin and insulin could not be excluded from our meta-analysis, and should be investigated in future trials.

The risks of other severe and non-severe adverse events were not significant between the two interventions. However, the number of dropouts from adverse events was significantly higher for metformin and insulin than for insulin alone in the fixed effect model. When initiating metformin treatment, participants often have gastrointestinal disturbances. ${ }^{1}$ The observed differences of the dropouts due to adverse events might have represented the initial adverse effects experienced when initiating metformin treatment, due to the short duration of the included trials. Therefore, the observed difference might have disappeared after the titration period of metformin, although no data were available to investigate this.

\section{Strengths and limitations}

Our systematic review has several strengths. We based it on a published protocol with rigid inclusion criteria for randomised clinical trials. ${ }^{15}$ We applied a comprehensive search with no language limitations or restrictions on outcomes reported in the trials. Two authors independently extracted data. We contacted corresponding authors of all trials to clarify methodological details and patient relevant outcomes, but only a few authors responded. We tried to evaluate the strength of the available evidence with comprehensive analyses of the risk of bias using subgroup analyses with test for subgroup differences and trial sequential analysis on all our primary and statistically significant secondary outcomes. ${ }^{21-24} \mathrm{We}$ evaluated the heterogeneity variance among trials.

The weaknesses of our analyses and conclusions mirror the weaknesses of the included trials. Our results should be interpreted with caution because almost all the trials had a high risk of bias. ${ }^{52-55}$ Data were sparse for patient relevant outcomes. Most trials had short duration of the intervention and assessed metabolic efficacy as their primary outcome. Only two trials had intervention duration longer than one year, ${ }^{64}$ and only one was designed to assess patient relevant outcomes. ${ }^{6}$

Subgroup analyses on the secondary outcomes showing significant results were post hoc. Nonetheless, the magnitude of $\mathrm{HbA}_{1 \mathrm{c}}$ reduction with metformin and insulin seemed to be more pronounced in trials designed to blind investigators and participants than in non-blinded trials. The extent to which this finding might be due to less aggressive titration of insulin doses in patients receiving both metformin and insulin in blinded trials than in non-blinded trials is unknown. Likewise, $\mathrm{HbA}_{1 \mathrm{c}}$ reductions were also more pronounced in trials using fixed insulin regimens than in those using variable regimens. The trials that used fixed regimens did not explain the exact meaning of this regimen; therefore, we cannot know if this regimen meant, for example, no changes in insulin type or dose. A fixed regimen strategy in terms of type or dose is probably unlikely to be found in clinical practice typically using unrestricted changes in insulin dose or type according to the individual needs of patients.

Despite these uncertainties and being a post hoc analysis, the data seem to raise a clinical dilemma: whether to reduce $\mathrm{HbA}_{1 \mathrm{c}}$ or change the insulin regimen (that is, mean difference in $\mathrm{HbA}_{1 \mathrm{c}}$ with variable regimen $-0.46 \% v$ mean difference with fixed regimen $-1.44 \% ; \mathrm{P}<0.001$ for test of interaction). This choice can only be better guided by randomised trials assessing patient relevant outcomes as well. Also, our finding of the influence of obesity on the reduction in insulin dose reiterates the classic, but as yet unsolved, question of metformin being a drug that potentially benefits mainly obese patients. ${ }^{5}$ Post hoc subgroup analysis of previous metformin treatment showed significant differences in the effect estimate of weight $(\mathrm{P}=0.03)$, showing a more pronounced weight reduction in trials not allowing metformin treatment at entry.

Because we aimed to assess the effect of metformin and insulin versus insulin alone irrespective of previous interventions, we included a diverse group of trials-for example, the percentage of patients who were insulin or metformin naive varied among trials. Furthermore, the prescribed insulin regimens varied markedly among trials, and some also varied between the intervention groups within the trials. ${ }^{3-47}$ Some trials allowed participants to receive metformin at trial entry. ${ }^{4.46} \mathrm{We}$ were unable to estimate for how long these participants received metformin, and only a few trials reported the percentage of participants receiving metformin at entry. Even though our subgroup analysis did not support a potential legacy effect of metformin, such an effect cannot be ruled out, because the absence of evidence is not evidence of absence.

\section{Results in relation to other studies and reviews}

A Cochrane review compared the effect of metformin alone with placebo or no intervention and found only a few trials providing data for mortality and morbidity. ${ }^{60}$ Accordingly, the review was inconclusive. A recent meta-analysis included a diverse group of trials of participants both with and without diabetes and showed a reduction of cardiovascular events with metformin (not necessarily alone) when compared with placebo, but, notably, not when compared with active comparators. ${ }^{7}$ Another meta-analysis including 10 trials showed that metformin alone reduced fasting blood glucose and $\mathrm{HbA}_{1 \mathrm{c}}$ compared with placebo, but did not report any significant difference in weight change. ${ }^{61}$ Another Cochrane review of 20 randomised clinical trials compared insulin and oral hypoglycaemic agents with insulin alone, but only few trials compared metformin and insulin with insulin alone. ${ }^{12}$ As in our review, evidence in that Cochrane review was insufficient to make conclusions about long term complications and mortality. The previous meta-analyses also included trials with high risk of bias and of short duration, similar to our systematic review.

We found no significant effect on cardiovascular complications, which conflicts with the findings of the HOME trial. The HOME trial found that metformin and insulin compared with insulin alone significantly reduced the risk of a composite outcome of cardiovascular complications after a follow-up of four years and four months when adjusted for baseline confounders. ${ }^{6}$ The reason for this difference cannot fully be elucidated. However, some obvious factors could be the differences in duration of intervention between trials with the lack of time to event analysis in a meta-analysis such as ours (without access to data at the patient level). Also, the sparse and possibly non-systematic or non-adjudicated reporting of events from studies other than the HOME trial could have been a confounder.

Moreover, the HOME trial reported baseline imbalances for some potentially important confounders, which could have influenced the results. The participants assigned to metformin and insulin were older (on average, five years) and had a history of cardiovascular disease more often than did the participants assigned placebo and insulin. On the other hand, the control group had more smokers than did the metformin and insulin group. The HOME trial authors found that the favourable effect 
of metformin could be explained partly by the metformin associated changes in weight. The HOME trial did not report $P$ values of the unadjusted events rates on macrovascular complications. Our analysis of macrovascular complications was mainly dominated by the results from the HOME trial reporting the unadjusted event rates. ${ }^{6}$

Observational studies comparing the effect of metformin and insulin with insulin monotherapy are sparse. We identified a Danish cohort study of patients with type 2 diabetes and heart failure (468 receiving metformin and insulin treatment, 3718 receiving insulin alone). ${ }^{62}$ The study showed reduced mortality in the combination group compared with insulin monotherapy, but did not report other potential benefits or harms. ${ }^{62}$

\section{Clinical implementations}

Many perceived disadvantages of insulin treatment in type 2 diabetes seem to be minimised by concomitant treatment with metformin. Metformin and insulin versus insulin alone seems to cause favourable reductions in weight, $\mathrm{HbA}_{\mathrm{c}}$, and insulin dose. However, we do not know of effects on patient relevant outcomes. The incomplete evidence on patient relevant outcomes is surprising, in view of current international consensus statements on diabetes clearly recommending the use of metformin and insulin in almost all patients with type 2 diabetes who initiate insulin treatment. ${ }^{263}$ Furthermore, as noted above, a recent meta-analysis ${ }^{7}$ did not confirm $(\mathrm{P}=0.89)$ the favourable effect of metformin on cardiovascular outcomes compared with other glucose lowering drugs, as observed in the UK Prospective Diabetes Study ${ }^{5}$ and possible harm of additional metformin treatment in sulphonylurea treated patients was suggested. ${ }^{7}$ Moreover, unlike insulin or sulphonylureas, metformin has not yet been shown to significantly reduce microvascular outcomes. $^{5-64}$

We thank Sarah Klingenberg, trials search coordinator of the Cochrane Hepato-Biliary Group, for her assistance in developing the search strategy; Dimitrinka Nikolova from the Cochrane Hepato-Biliary Group for translating the Russian article; and Suzanne Strowig and Udaya Kabadi for providing data.

Contributors: BH undertook the searches and data analysis. BH, LLC, and TA participated in the selection of trials, data extraction, and quality assessment of trials. JW advised on statistical methods and data analyses. CG advised on statistical methods and interpretation of data. All authors developed the protocol, read and approved the final manuscript, and were involved in the development of the final review. $\mathrm{BH}$ and TA are the guarantors.

Funding: This study received funding from the Copenhagen Trial Unit, Centre for Clinical Intervention Research, Rigshospitalet, Denmark (the Copenhagen Insulin and Metformin Therapy Trial Group). The funding source had no role in the design and conduct of the study; the extraction, management, analysis, or interpretation of the data; or the preparation, review, or approval of the manuscript.

Competing interests: All authors have completed the ICMJE uniform disclosure form at www.icmje.org/coi_disclosure.pdf (available on request from the corresponding author) and declare that: the study received funding from the Copenhagen Insulin and Metformin Therapy Trial Group; LLC, SSL, AV, and TA have reported equity in Novo Nordisk A/S; SSL and AV have received fees from Novo Nordisk A/S for speech making; LLC was employed at Steno Diabetes Centre, Gentofte, Denmark, when the systematic review began; TA is employed at Steno Diabetes Center, which is an academic institution owned by Novo Nordisk A/S; BH, JW, and CG have no conflicts of interest to declare; after the initial draft of the present manuscript, SSL took up a position at Boehringer Ingelheim, Ingelheim, Germany.
Ethical approval: Not required.

Data sharing: No additional data available.

American Hospital Formulary Service Drug Information. Metformin hydrochloride. American Society of Health-System Pharmacists Inc, 1999;2755-63.

2 Nathan DM, Buse JB, Davidson MB, Ferrannini E, Holman RR, Sherwin R, et al. Medical management of hyperglycaemia in type 2 diabetes mellitus: a consensus algorithm for the initiation and adjustment of therapy: a consensus statement from the American Diabetes Association and the European Association for the Study of Diabetes. Diabetologia 2009;52:17-30.

3 Yki-Järvinen H, Ryysy L, Nikkilä K, Tulokas T, Vanamo R, Heikkilä M. Comparison of bedtime insulin regimens in patients with type 2 diabetes mellitus. A randomized, controlled trial. Ann Intern Med 1999;130:389-96.

4 Douek IF, Allen SE, Ewings P, Gale EAM, Bingley PJ. Continuing metformin when starting insulin in patients with type 2 diabetes: a double-blind randomized placebo-controlled trial. Diabet Med 2005;22:634-40.

5 UK Prospective Diabetes Study (UKPDS) Group. Effect of intensive blood-glucose control with metformin on complications in overweight patients with type 2 diabetes (UKPDS 34). Lancet 1998;352:854-65.

6 Kooy A, de Jager J, Lehert P, Bets D, Wulffelé MG, Donker AJ, et al. Long-term effects of metformin on metabolism and microvascular and macrovascular disease in patients with type 2 diabetes mellitus. Arch Intern Med 2009;169:616-25.

7 Lamanna C, Monami M, Marchionni N, Mannucci E. Effect of metformin on cardiovascular events and mortality: a meta-analysis of randomized clinical trials. Diabet Obesity Metab 2011;13:221-8.

8 Massi-Benedetti M, Orsini-Federici M. Treatment of type 2 diabetes with combined therapy: what are the pros and cons? Diabetes Care 2008;31(suppl 2):131-5.

9 Riddle MC. Timely addition of insulin to oral therapy for type 2 diabetes. Diabetes Care 2001;25:395-6.

10 Vella S, Buetow L, Royle P, Livingstone S, Colhoun HM, Petrie JR. The use of metformin in type 1 diabetes: a systematic review of efficacy. Diabetologia 2010;53:809-20.

11 Wulffele MG, Kooy A, de Zeeuw D, Stehouwer CDA, Gansevoort RT. The effect of metformin on blood pressure, plasma cholesterol and triglycerides in type 2 diabetes mellitus: a systematic review. J Intern Med 2004;256:1-14.

12 Goudswaard AN, Furlong NJ, Rutten GE, Stolk RP, Valk GD. Insulin monotherapy versus combinations of insulin with oral hypoglycaemic agents in patients with type 2 diabetes mellitus. Cochrane Database Syst Rev 2004;4:CD003418.

13 Bennett WL, Maruthur NM, Singh S, Segal JB, Wilson LM, Chatteriee R, et al. Comparative effectiveness and safety of medications for type 2 diabetes: an update including new drugs and 2-drug combinations. Ann Intern Med 2011;154:602-13.

14 Higgins JPT, Green S, eds. Cochrane handbook for systematic reviews of interventions. Version 5.1.0. The Cochrane Collaboration, 2011.

15 Hemmingsen B, Christensen LL, Wetterslev J, Vaag A, Gluud C, Lund SS, et al. Metformin plus insulin combination therapy compared with insulin monotherapy for patients with type 2 diabetes mellitus. 2011. http://goo.gl/3YRd8

16 The Cochrane Collaboration. Review manager (RevMan) [computer program]. Version 5.1. The Nordic Cochrane Centre, the Cochrane Collaboration, 2011.

17 Wulffele MG, Kooy A, Lehert P, Bets D, Ogterop JC, Van Der Burg BB, et al. Combination of insulin and metformin in the treatment of type 2 diabetes. Diabetes Care 2002;25:2133-40.

18 Relimpio F, Pumar A, Losada F, Mangas MA, Acosta D, Astorga R. Adding metformin versus insulin dose increase in insulin-treated but poorly controlled type 2 diabetes mellitus: an open-label randomized trial. Diabet Med 1998;15:997-1002.

19 DerSimonian R, Laird N. Meta-analysis in clinical trials. Control Clin Trials 1986;7:177-88.

20 DeMets DL. Methods for combining randomized clinical trials: strengths and limitations. Stat Med 1987;6:341-50.

21 Brok J, Thorlund K, Gluud C, Wetterslev J. Trial sequential analysis reveals insufficient information size and potentially false positive results in many meta-analyses. J Clin Epidemiol 2008;61:763-9.

22 Brok J, Thorlund K, Wetterslev J, Gluud C. Apparently conclusive meta-analyses may be inconclusive-trial sequential analysis adjustment of random error risk due to repetitive testing of accumulating data in apparently conclusive neonatal meta-analyses. Int $J$ Epidemiol 2009;38:287-98.

23 Thorlund K, Devereaux PJ, Wetterslev J, Guyatt G, loannidis JP, Thabane L, et al. Can trial sequential monitoring boundaries reduce spurious inferences from meta-analyses? Int J Epidemiol 2009;38:276-86.

24 Wetterslev J, Thorlund K, Brok J, Gluud C. Trial sequential analysis may establish when firm evidence is reached in cumulative meta-analysis. J Clin Epidemiol 2008;61:64-75.

25 Thorlund K, Engstrøm J, Wetterslev J, Brok J, Imberger G, Gluud C. User manual for Trial Sequential Analysis (TSA). Copenhagen Trial Unit, Centre for Clinical Intervention Research, The Copenhagen, Denmark. 2011; 1-115. www.ctu.dk/tsa.

26 Thorlund K, Imberger G, Walsh M, Chu R, Gluud C, Wetterslev J, et al. The number of patients and events required to limit the risk of overestimation of intervention effects in meta-analysis-a simulation study. PLoS One 2011;10:1371.

27 The Copenhagen Trial Unit. Trial sequential analysis [computer program]. Version 0.9 beta. The Copenhagen Trial Unit, Centre for Clinical Intervention Research, 2011. www. ctu.dk/tsa.

28 Wetterslev J, Thorlund K, Brok J, Gluud C. Estimating required information size by quantifying diversity in random-effects model meta-analyses. BMC Med Res Methodol 2009;9:86-98.

29 Heine RJ, Scheen A, Van Gaal L, Schmitt H, Van der Waal PS. Efficacy of bedtime NPH insulin alone, as compared to combination with metformin and/or glipizide in NIDDM patients with secondary failure on oral hypoglycaemic agents. Neth J Med 1995;47:A59-60.

30 Robinson AC, Burke J, Robinson S, Johnston DG, Elkeles RS. The effects of metformin on glycemic control and serum lipids in insulin-treated NIDDM patients with suboptimal metabolic control. Diabetes Care 1998;21:701-5.

31 Schnack C, Biesenbach G, Kacerovsky G, Mihaljevic R, Pecnik I, Pieber T, et al. Evaluation of optimal therapy in type-2 diabetic patients insufficiently treated with sulfonylureas: the Austrian insulin intervention study. Diabetologia 1996;39(suppl 1):A33.

32 Van der Waal PS, Scheen A, van Gaal L, Schmitt H, Heine RJ. Efficacy of bedtime NPH insulin alone, as compared to combination with metformin and/or gliplizide in NIDDM patients with secondary failure to oral hypoglycemic agents. Diabetes 1996;45:286A. 


\section{What is already known on this topic}

Because of the progressive nature of type 2 diabetes, a substantial proportion of patients end up receiving insulin treatment Current guidelines for diabetes treatment recommend combining metformin with insulin instead of using insulin alone Previous meta-analyses have only included a few trials comparing metformin and insulin with insulin alone

\section{What this study adds}

The reporting of patient relevant outcomes was sparse

An influence of metformin and insulin versus insulin alone on all cause mortality or cardiovascular mortality could not be established, and more trials are needed to provide firm evidence for an effect or absence of an effect

Metformin and insulin treatment, compared with insulin alone, seems to be associated with a reduction in $\mathrm{HbA}_{10}$, weight gain, and insulin dose

Metformin and insulin seems to increase the risk of severe hypoglycaemia compared with insulin alone

33 Van der Waal PS, Scheen A, Van Gaal L, Schmitt H, Heine RJ. Predictors of glycaemic efficacy of four treatment strategies in NIDDM patients with secondary failure to oral hypoglycaemic agents. Neth J Med 1996;48:A49.

34 Hirsch IB. Metformin added to insulin therapy in poorly controlled type 2 diabetes. Diabetes Care 1999;22:854.

35 Ponssen HH, Elte JW, Lehert P, Schouten JP, Bets D. Combined metformin and insulin therapy for patients with type 2 diabetes mellitus. Clin Ther 2000;22:709-18.

36 Civera M, Merchante A, Salvador M, Sanz J, Martínez I. Safety and efficacy of repaglinide in combination with metformin and bedtime NPH insulin as an insulin treatment regimen in type 2 diabetes. Diabet Res Clin Pract 2008:79:42-7.

37 Galani V, Patel HM. Comparison of metformin and insulin monotherapy with combined metformin and insulin therapy in patients of type 2 diabetes with $\mathrm{HbA1C}>7 \%$. Int $J$ Pharmaceutical Biol Arch 2011;2:563-8.

38 Kabadi UM, Kabadi M. Comparative efficacy of glimepiride and/or metformin with insulin in type 2 diabetes. Diabet Res Clin Pract 2006;72:265-70.

39 Kvapil M, Swatko A, Hilberg C, Shestakova M. Biphasic insulin aspart 30 plus metformin: an effective combination in type 2 diabetes. Diabet Obes Metab 2006;8:39-48.

40 Onuchin SG, Elsukova OS, Solov'ev OV, Onuchina EL. [Capabilities of hypoglycemic therapy in women with decompensated type 2 diabetes mellitus.] [In Russian.] Terapevticheskii Arkhiv 2010;82:34-41.

41 Ushakova O, Sokolovskaya V, Morozova A, Valeeva F, Zanozina O, Sazonova O, et al. Comparison of biphasic insulin aspart 30 given three times daily or twice daily in combination with metformin versus oral antidiabetic drugs alone in patients with poorly controlled type 2 diabetes: a 16-week, randomized, open-label, parallel-group trial conducted in Russia. Clin Ther 2007;29:2374-84.

42 Kokic S, Bukovic D, Radman M, Capkun V, Gabric N, Lesko V, et al. Lispro insulin and metformin versus other combination in the diabetes mellitus type 2 management after secondary oral antidiabetic drug failure. Collegium Antropologicum 2003;27:181-7.

43 Altuntas Y, Ozen B, Ozturk B, Sengul A, Ucak S, Ersoy O, et al. Comparison of additional metformin or NPH insulin to mealtime insulin lispro therapy with mealtime human insulin therapy in secondary OAD failure. Diabet Obes Metab 2003;5:371-8.

44 Gram J, Henriksen JE, Grodum E, Juhl H, Hansen TB, Christiansen C, et al. Pharmacological treatment of the pathogenetic defects in type 2 diabetes: the randomized multicenter South Danish Diabetes Study. Diabetes Care 2011;34:27-33

45 Kokic S, Kokic V, Krnic M, Miric L, Jovanovic Z, Orlic-Crncevic Z. Advantage of prandial insulin as a therapeutic approach in initial secondary pancreatic beta-cell exhaustion in type 2 diabetic patients. Diabetologia Croatica 2010;39:37-42.

46 Vähätalo M, Rönnemaa T, Viikari J. Recognition of fasting or overall hyperglycaemia when starting insulin treatment in patients with type 2 diabetes in general practice. Scand J Prim Health Care 2007:25:147-53.

47 Strowig SM, Avilés-Santa ML, Raskin P. Comparison of insulin monotherapy and combination therapy with insulin and metformin or insulin and troglitazone in type 2 diabetes. Diabetes Care 2002;25:1691-8.

48 Avilés-Santa L, Sinding J, Raskin P. Effects of metformin in patients with poorly controlled, insulin-treated type 2 diabetes mellitus. A randomized, double-blind, placebo-controlled trial. Ann Intern Med 1999;131:182-8.

49 Giugliano D, Quatraro A, Consoli G, Minei A, Ceriello A, De Rosa N, et al. Metformin for obese, insulin-treated diabetic patients: improvement in glycaemic control and reduction of metabolic risk factors. Eur J Clin Pharmacol 1993;44:107-12.

50 Hermann LS, Kalén J, Katzman P, Lager I, Nilsson A, Norrhamn O, et al. Long-term glycaemic improvement after addition of metformin to insulin in insulin-treated obese type 2 diabetes patients. Diabet Obes Metab 2001;3:428-34.
51 Yilmaz H, Gursoy A, Sahin M, Guvener Demirag N. Comparison of insulin monotherapy and combination therapy with insulin and metformin or insulin and rosiglitazone or insulin and acarbose in type 2 diabetes. Acta Diabetologica 2007:44:187-92.

52 Schulz KF, Chalmers I, Hayes RJ, Altman DG. Empirical evidence of bias. Dimensions of methodological quality associated with estimates of treatment effects in controlled trials. JAMA 1995;273:408-12.

53 Moher D, Pham B, Jones A, Cook DJ, Jadad AR, Moher M, et al. Does quality of reports of randomised trials affect estimates of intervention efficacy reported in meta-analyses? Lancet 1998;352:609-13.

54 Kjaergard LL, Villumsen J, Gluud C. Reported methodological quality and discrepancies between small and large randomized trials in meta-analyses. Ann Intern Med 2001;135:982-9.

55 Wood L, Egger M, Gluud LL, Schulz KF, Jüni P, Altman GD, et al. Empirical evidence of bias in treatment effect estimates in controlled trials with different interventions and outcomes: meta-epidemiological study. BMJ 2008;336:601-5.

56 Gluud C, Brok J, Gong Y, Koretz RL. Hepatology may have problems with putative surrogate outcome measures. J Hepatol 2007;46:734-42.

57 Food and Drug Administration. Guidance for industry: diabetes mellitus-evaluating cardiovascular risk in new antidiabetic therapies to treat type 2 diabetes. 2008. Access link here.

58 Hemmingsen B, Lund SS, Gluud C, Vaag A, Almdal T, Hemmingsen C, et al. Targeting intensive glycaemic control versus targeting conventional glycaemic control for type 2 diabetes mellitus. Cochrane Database Syst Rev 2011;6:CD008143.

59 Hemmingsen B, Lund SS, Gluud C, Vaag A, Almdal T, Hemmingsen C, et al. Intensive glycaemic control for patients with type 2 diabetes: systematic review with meta-analysis and trial sequential analysis of randomised clinical trials. BMJ 2011;343:d6898.

60 Saenz A, Fernandez-Esteban I, Mataix A, Segura MA, Figuls M, Moher D. Metformin monotherapy for type 2 diabetes mellitus. Cochrane Database Syst Rev 2005;3:CD002966.

61 Johansen K. Efficacy of metformin in the treatment of NIDDM: meta-analysis. Diabetes Care 1999;22:33-7.

62 Andersson C, Olesen JB, Hansen PR, Weeke P, Norgaard ML, Jorgensen CH, et al. Metformin treatment is associated with a low risk of mortality in diabetic patients with heart failure: a retrospective nationwide cohort study. Diabetologia 2010;53:2546-53.

63 International Diabetes Federation Clinical Guidelines Task Force. An evidence-based guideline to type 2 diabetes using a novel concept of levels of care to make it applicable across the globe. International Diabetes Federation, 2005.

64 Holman RR, Paul SK, Bethel MA, Matthews DR, Neil HA. 10-year follow-up of intensive glucose control in type 2 diabetes. N Engl J Med 2008;359:1577-89.

65 South Danish Diabetes Study. Evaluation of the antidiabetic treatment of type 2 diabetes mellitus (SDDS). 2011. http://clinicaltrials.gov/ct2/show/NCT00121966.

66 Ryysy L, Yki-Järvinen $\mathrm{H}$. Improvement of glycemic control by 1 year of insulin therapy leads to a sustained decrease in $\mathrm{SE}$-selectin concentrations in type 2 diabetes. Diabetes Care 2001;24:549-54.

\section{Accepted: 03 February 2012}

\section{Cite this as: BMJ 2012;344:e1771}

This is an open-access article distributed under the terms of the Creative Commons Attribution Non-commercial License, which permits use, distribution, and reproduction in any medium, provided the original work is properly cited, the use is non commercial and is otherwise in compliance with the license. See: http://creativecommons.org/licenses/bync/2.0/ and http://creativecommons.org/licenses/by-nc/2.0/legalcode. 


\section{Tables}

\begin{tabular}{|c|c|c|c|c|c|c|c|}
\hline Trial & $\begin{array}{c}\text { No of } \\
\text { participants }\end{array}$ & Age (years) ${ }^{*}$ & $\begin{array}{c}\text { Duration of } \\
\text { diabetes (years) }\end{array}$ & HbA1c (\%)* & Weight $(\mathbf{k g})^{*}$ & Body mass index & $\begin{array}{l}\text { Trial duration } \\
\text { (months) }\end{array}$ \\
\hline Altuntas et al, $2003^{43}$ & $20 / 40$ & $\begin{array}{c}53.8(13.9) / 54.7 \\
(33.5)\end{array}$ & $5.2 / 8.2$ & $10.1(5.1) / 9.5(6.5)$ & NR & $\begin{array}{c}31.2(34.9) / 31.6 \\
(14.5)\end{array}$ & 6 \\
\hline $\begin{array}{l}\text { Avilés-Santa et al, } \\
1999^{48}\end{array}$ & $21 / 22$ & $53.1(9.4) / 54.6(7.8)$ & $9.2(6.4) / 10.1(4.7)$ & $9.0(1.4) / 9.1(1.5)$ & $\begin{array}{c}103.9(25.2) / 106.6 \\
(12.2)\end{array}$ & NR & 6 \\
\hline Civera et al, $2007^{36}$ & $12 / 13$ & $61.6(9.2) / 61.8(10.2)$ & $7.9(3.3) / 11.1(6.7)$ & $9.6(0.7) / 9.8(1.1)$ & $\begin{array}{c}74.7(8.0) / 68.8 \\
(14.7)\end{array}$ & $27.9(3.8) / 27.4(4.8)$ & 6 \\
\hline Douek et al, $2005^{4}$ & $92 / 91$ & $58(8.9) / 58(7.7)$ & $9(5.2) / 10(5.2)$ & $9.7(1.3) / 10.0(1.5)$ & $\begin{array}{c}88.5(14.7) / 91.1 \\
(15.7)\end{array}$ & $30.9(4.5) / 31.5(4.3)$ & 12 \\
\hline Galvani et al, $2011^{37}$ & $15 / 15$ & $55.2 / 61.4$ & NR & $10.8(0.7) / 9.6(0.7)$ & $65.1 / 65.4$ & NR & 3 \\
\hline Giugliano et al, $1992^{49}$ & $27 / 23$ & $60(1) / 60.8(1.1)$ & $11.9(1.2) / 11.5(1.2)$ & $11.5(1.2) / 11.7(1.3)$ & NR & $33(3.1) / 32.7(3.2)$ & 6 \\
\hline Heine et al, $1995^{29,32,33}$ & $134 \dagger$ & NR & NR & $13.6 / 13.4$ & NR & $\begin{array}{l}\text { Both groups: } 29.0 \\
(3.0)\end{array}$ & 6 \\
\hline Hermann et al, $2001^{50}$ & $16 / 19$ & $56.9(10.2) / 58.1(9.7)$ & $13(3-13) / 13(4-25)$ & $9.1(1.3) / 8.7(1.0)$ & $\begin{array}{c}96.4(16.6) / 94.2 \\
(9.4) \\
\end{array}$ & $33.6(3.5) / 32.6(3.8)$ & 12 \\
\hline Hirsch et al, $1999^{34}$ & $25 / 25$ & NR & NR & $8.6(1.1) / 9.0(1.8)$ & NR & NR & 5 \\
\hline HOME, $2009^{6,17}$ & $196 / 194$ & $64(10) / 59(11)$ & $14(9) / 12(8)$ & $7.9(1.2) / 7.9(1.2)$ & $85(16) / 87(15)$ & $30(5) / 30(5)$ & 4.3 \\
\hline Kabadi et al, $2006^{38}$ & $12 / 8$ & $54(24.2) / 53(17.0)$ & $13(13.9) / 13(11.3)$ & $9.4(4.2) / 9.6(3.1)$ & $98(27) / 103(28.3)$ & $34(17.3) / 35(14.1)$ & 6 \\
\hline Kokic et al, $2003^{42}$ & $29 / 29$ & $62.3(7.2) / 63.6(4.8)$ & $9.5(3.1) / 10.5(3.2)$ & $\begin{array}{c}10.0(1.73) / 9.21 \\
(1.54)\end{array}$ & NR & $30.2(4.8) / 27.9(3.9)$ & 3 \\
\hline Kokic et al, $2010^{45}$ & $79 / 79$ & $64.2(8.4) / 66.0(12.7)$ & $9.5(3.6) / 10.0(6.2)$ & $10.2(2.1) / 9.5(2.0)$ & NR & $28.9(3.5) / 28.5(3.5)$ & 6 \\
\hline Kvapil et al, $2005^{39} \ddagger$ & $116 / 111$ & $56.4(9.0) / 55.2(10.3)$ & $6.7(5.7) / 8.2(7.1)$ & $9.3(1.3) / 9.6(1.5)$ & $\begin{array}{c}85.1(15.1) / 87.3 \\
(16.5)\end{array}$ & $30.4(4.0) / 30.9(4.5)$ & 4 \\
\hline Onuchin et al, $2010^{40}$ & $44 / 45$ & $61.4(8.0) / 61.1(8.5)$ & $8(6-13) / 9(4-14) \S$ & $10.8(1.6) / 11.03(1.9)$ & $\mathrm{NR}$ & $32.3(5.7) / 31.1(7.6)$ & 12 \\
\hline Ponssen et al, $2000^{35}$ & $17 / 14$ & $63.7(10.0) / 59.4(9.7)$ & $10(96-276) \ddagger$ & NR & 72.2 & $N R$ & $\begin{array}{l}5 \text { (before } \\
\text { crossover) }\end{array}$ \\
\hline Relimpio et al, $1998^{18}$ & $31 / 29$ & $65.4(7.9) / 66.7(6.2)$ & $15.4(7.9) / 15.3(6)$ & $9.6(1.4) / 9.6(1.2)$ & $\begin{array}{c}76.8(12.6) / 78.0 \\
(12.9)\end{array}$ & $33(4.7) / 31.9(4.5)$ & 4 \\
\hline $\begin{array}{l}\text { Robinson et al, } 1998 \\
\text { study } 1^{30}\end{array}$ & 20 I & $61.3(7.1)$ & $15(7)$ & $8.9(1.0)$ & $81.1(16.9)$ & $29.5(3.5)$ & $\begin{array}{l}3 \text { (before } \\
\text { crossover) }\end{array}$ \\
\hline $\begin{array}{l}\text { Robinson et al, } 1998 \\
\text { study } 2^{30}\end{array}$ & 15 I & $56.1(8.9)$ & $14(6)$ & $9.5(1.2)$ & $83.2(12.7)$ & $30.9(3.8)$ & $\begin{array}{l}3 \text { (before } \\
\text { crossover }\end{array}$ \\
\hline Schnack et al, $1996^{31}$ & $20 / 19^{\star \star}$ & 63.3 & 11.3 & $10.0(0.9) / 9.7(0.9)$ & $\begin{array}{c}77.2(11.2) / 81.1 \\
(16.1)\end{array}$ & NR & 6 \\
\hline SDDSa, $2011^{44,65}$ & $45 / 46$ & $55.4(8.5) / 55.8(7.7)$ & $8.2(4.0) / 7.3(4.3)$ & $8.9(1.2) / 8.7(1.3)$ & $\begin{array}{c}105(17.7) / 100.2 \\
(19.8)\end{array}$ & $35.7(6.4) / 34.0(6.0)$ & 24 \\
\hline SDDSb, $2011^{44,65}$ & $45 / 48$ & $56.1(8.2) / 57.1(8.5)$ & $8.7(4.5) / 9.1(5.5)$ & $8.5(1.2) / 8.5(1.2)$ & $\begin{array}{c}100.5(17.9) / 98.3 \\
(16.6)\end{array}$ & $33.7(6.1) / 33.7(5.0)$ & 24 \\
\hline Strowig et al, $2002^{47}$ & $30 / 31$ & $51.8(10.5) / 54.4(9.1)$ & $7.6(4.1) / 10.5(7.3)$ & $8.8(1.2) / 8.7(1.6)$ & $\begin{array}{c}105.8(22.4) / 107.0 \\
(26.7)\end{array}$ & $37.1(6.6) / 36.4(9.0)$ & 4 \\
\hline Ushakova et al, $2007^{41}$ & $100 / 104$ & $58.4(6.4) / 58.0(6.4)$ & $8.4(5.7) / 9.9(6.2)$ & $10.4(1.7) / 10.4(1.4)$ & $\begin{array}{c}78.4(13.0) / 79.3 \\
(11.8)\end{array}$ & $29.2(3.8) / 29.8$ (3.5) & 4 \\
\hline Vähätalo et al, $2007^{46}$ & $26 / 11$ & NR & NR & $10 / 9.8$ & $81.7 / 85.1$ & $\mathrm{NR}$ & 12 \\
\hline Yilmaz et al, $2007^{51}$ & $17 / 19$ & $57.7(8.5) / 61.5(12.0)$ & $\begin{array}{c}12.1(7.7) / 17.9 \\
(11.5)\end{array}$ & $8.9(1.2) / 8.7(1.6)$ & $\begin{array}{c}79.4(14.1) / 71.7 \\
(16.0)\end{array}$ & $33.2(6.1) / 28.2(5.9)$ & 6 \\
\hline $\begin{array}{l}\text { Yki-Järvinen et al, } \\
1999^{3.66}\end{array}$ & $23 / 24$ & (9.8) & NR & .0) & NR & (5.4) & 12 \\
\hline
\end{tabular}

NR=not reported; SDDS=South Danish Diabetes Study; SDDSa=intervention group in the South Danish Diabetes Study prescribed neutral protamine Hagedorn insulin in combination with metformin or placebo; SDDSb=intervention group in the South Danish Diabetes Study prescribed insulin aspart in combination with metformin or placebo; Robinson study 1 =participants were exclusively treated with insulin at entry to trial and randomised to metformin or placebo in addition to insulin; Robinson study 2=participants received combination of metformin and insulin at entry to the trial, but after entry to the trial participants were randomised to receive either metformin or placebo. 
Table 1 (continued)

\begin{tabular}{|c|c|c|c|c|c|c|c|}
\hline Trial & $\begin{array}{c}\text { No of } \\
\text { participants }\end{array}$ & Age (years)* & $\begin{array}{c}\text { Duration of } \\
\text { diabetes (years) }\end{array}$ & HbA1c (\%)* & Weight (kg)* & Body mass index* & $\begin{array}{l}\text { Trial duration } \\
\text { (months) }\end{array}$ \\
\hline
\end{tabular}

*Data are intervention group (insulin and metformin)/control group (insulin (and placebo)); data for continuous variables are mean (standard deviation) if reported, unless stated otherwise.

†Number of participants randomly assigned into four groups, of which only two were relevant for our review.

$\ddagger$ Baseline data only reported for participants exposed, not those who underwent randomisation.

§Interquartile range.

TData only reported for the total number of participants undergoing randomisation.

${ }^{* \star}$ More participants were randomly assigned to each group and only data for the one trial with available data reported. 


\begin{tabular}{|c|c|c|c|c|c|c|c|}
\hline \multirow[b]{2}{*}{ Trial } & \multirow{2}{*}{$\begin{array}{c}\text { Systolic and } \\
\text { diastolic blood } \\
\text { pressure (mm } \\
\mathrm{Hg})^{\star}\end{array}$} & \multicolumn{3}{|c|}{ Cholesterol concentration $(\mathrm{mmol} / \mathrm{L})^{*}$} & \multirow{2}{*}{$\begin{array}{l}\text { Triglyceride } \\
\text { concentration } \\
(\mathrm{mmol} / \mathrm{L})^{*}\end{array}$} & \multirow{2}{*}{$\begin{array}{l}\text { No of patients } \\
\text { given aspirin, } \\
\text { antihypertensive, } \\
\text { or lipid lowering } \\
\text { treatment }\end{array}$} & \multirow{2}{*}{$\begin{array}{l}\text { Previous } \\
\text { cardiovascular } \\
\text { disease }^{\star}\end{array}$} \\
\hline & & Total & $\begin{array}{l}\text { Low density } \\
\text { lipoprotein }\end{array}$ & $\begin{array}{l}\text { High density } \\
\text { lipoprotein }\end{array}$ & & & \\
\hline Altuntas et al, $2003^{43}$ & NR & $5.8(8.0) / 5.3(5.4)$ & $3.3(0.9) / 3.1(4.3)$ & $1.3(0.9) / 1.1(0.9)$ & $3.6(13.0) / 2.2(4.7)$ & NR & NR \\
\hline $\begin{array}{l}\text { Avilés-Santa et al, } \\
1999^{48}\end{array}$ & NR & $5.5(1.0) / 5.6(1.5)$ & $3.1(0.8) / 3.5(1.1)$ & $0.9(0.3) / 0.9(0.3)$ & $2.3(1.3) / 2.5(2.1)$ & NR & NR \\
\hline Civera et al, $2007^{36}$ & $\begin{array}{l}146(26) / 78(10) ; \\
152(23) / 81(11)\end{array}$ & NR & NR & NR & NR & NR & NR \\
\hline Douek et al, $2005^{4}$ & $\begin{array}{l}146(20) / 84(11) \\
145(19) / 84(11)\end{array}$ & $\begin{array}{c}5.1(0.96) / 5.1 \\
(0.98)\end{array}$ & NR & $\begin{array}{c}1.1(0.22) / 1.1 \\
(0.33)\end{array}$ & $2.9(2.0) / 2.5(1.4)$ & NR & NR \\
\hline Galani et al, $2011^{37}$ & $\begin{array}{l}136.9 / 80.7 \\
136.4 / 79.8\end{array}$ & NR & NR & NR & NR & NR & NR \\
\hline Giugliano et al, $1992^{49}$ & $\begin{array}{c}155(20) / 87.5(10) \\
155(20) / 85(10)\end{array}$ & $\begin{array}{c}5.9(0.6) / 6.03 \\
(0.6)\end{array}$ & NR & $1.05(0.3) / 1.0(0.3)$ & $2.9(0.9) / 2.6(0.5)$ & $\begin{array}{l}N R / 5 / N R \\
N R / 4 / N R\end{array}$ & NR \\
\hline Heine et al, $1995^{29,32,33}$ & NR & NR & NR & NR & NR & NR & NR \\
\hline Hermann et al, $2001^{50}$ & $\begin{array}{c}155(17) / 84(8) ; 153 \\
(17) / 88(9)\end{array}$ & $6.1(1.2) / 6.0(1.3)$ & $3.9(0.8) / 3.7(1.3)$ & $1.2(0.3) / 1.1(0.3)$ & $2.8(1.7) / 2.5(1.3)$ & NR & $\begin{array}{l}19 \% \text { of included } \\
\text { participants }\end{array}$ \\
\hline Hirsch et al, $1999^{34}$ & NR & NR & NR & NR & NR & NR & NR \\
\hline HOME, $2009^{6,17}$ & $\begin{array}{l}160(25) / 86(12) ; \\
159(25) / 86(11)\end{array}$ & $5.5(1.3) / 5.4(1.2)$ & $3.6(1.1) / 3.4(1.0)$ & $1.3(0.4) / 1.3(0.4)$ & $1.7(1.2) / 1.9(1.5)$ & $\begin{array}{l}\mathrm{NR} / 93 / 32 \\
\mathrm{NR} / 75 / 31\end{array}$ & $59 / 53+$ \\
\hline Kabadi et al, $2006^{38}$ & NR & NR & NR & NR & NR & NR & NR \\
\hline Kokic et al, $2003^{42}$ & NR & NR & NR & NR & NR & NR & NR \\
\hline Kokic et al, $2010^{45}$ & NR & NR & NR & NR & NR & NR & NR \\
\hline Kvapil et al, $2005^{39}$ & NR & NR & NR & $1.2(0.3) / 1.2(0.3)$ & $2.8(2.4) / 2.6(2.5)$ & NR & NR \\
\hline Onuchin et al, $2010^{40}$ & $\begin{array}{c}161(22.1) / 93.2 \\
(8.5) ; 161 \\
(23.2) / 94.9(8.3)\end{array}$ & $6.3(1.4) / 6.5(1.6)$ & NR & NR & $3.4(1.4) / 3.0(1.5)$ & NR & NR \\
\hline Ponssen et al, $2000^{35}$ & NR & NR & NR & NR & NR & NR & NR \\
\hline Relimpio et al, $1998^{18}$ & $\begin{array}{c}153.5(24) / 81.6 \\
(10.8) ; 148 .(24.8) / 80 \\
(14.4)\end{array}$ & $\begin{array}{c}5.84(1.0) / 5.92 \\
(1.2)\end{array}$ & $\begin{array}{c}3.84(0.51) / 3.71 \\
(1.15)\end{array}$ & $\begin{array}{c}1.36(0.18) / 1.34 \\
(0.35)\end{array}$ & $\begin{array}{c}2.01 \\
(1.1) / 2.42(1.53)\end{array}$ & $\begin{array}{l}N R / 10 / 1 \\
N R / 7 / 5\end{array}$ & $13 / 13 \ddagger$ \\
\hline $\begin{array}{l}\text { Robinson et al, } 1998, \\
\text { study } 1^{30}\end{array}$ & $138(16) / 78(9) \S$ & $6.0(1.1)$ & $3.9(1.2)$ & $1.1(0.3)$ & $2.2(1.3)$ & NR & NR \\
\hline $\begin{array}{l}\text { Robinson et al, } 1998 \\
\text { study } 2^{30}\end{array}$ & $144(23) / 87(11) \S$ & $6.4(1.2)$ & $4.1(1.5)$ & $1.2(0.4)$ & $2.5(2.4)$ & NR & NR \\
\hline Schnack et al, $1996^{31}$ & $\mathrm{NR}$ & NR & NR & NR & NR & NR & NR \\
\hline SDDSa, $2011^{44,65}$ & NR & NR & NR & NR & NR & NR & NR \\
\hline SDDSb, $2011^{44,65}$ & NR & NR & NR & NR & NR & NR & NR \\
\hline Strowig et al, $2002^{47}$ & $\mathrm{NR}$ & $4.9(1.1) / 4.9(1.1)$ & $2.8(1.1) / 2.8(0.7)$ & $0.8(0.2) / 1.0(0.3)$ & $2.5(1.8) / 2.0(1.7)$ & NR & NR \\
\hline Ushakova et al, $2007^{41}$ & NR & NR & NR & NR & NR & NR & NR \\
\hline Vähätalo et al, $2007^{46}$ & NR & NR & NR & NR & NR & NR & NR \\
\hline Yilmaz et al, $2007^{51}$ & NR & $4.6(0.7) / 5.4(1.8)$ & $2.5(0.6) / 3.2(0.5)$ & $1.3(0.4) / 1.3(0.2)$ & $1.7(0.9) / 2.5(2.4)$ & NR & NR \\
\hline $\begin{array}{l}\text { Yki-Järvinen et al, } \\
1999^{3,66}\end{array}$ & NR & $5.9(1.4) / 5.8(1.5)$ & NR & $1.2(0.5) / 1.2(0.5)$ & $2.4(1.9) / 0.9(2.4)$ & $N R / 2 / N R$ & NR \\
\hline
\end{tabular}

NR=not reported; SDDS=South Danish Diabetes Study; SDDSa=intervention group in the South Danish Diabetes Study prescribed neutral protamine Hagedorn insulin in combination with metformin or placebo; SDDSb=intervention group in the South Danish Diabetes Study prescribed insulin aspart in combination with metformin or placebo; Robinson study 1=participants were exclusively treated with insulin at entry to trial and randomised to metformin or placebo in addition to insulin; Robinson study 2=participants received combination of metformin and insulin at entry to the trial, but after entry to the trial participants were randomised to receive either metformin or placebo.

*Data are intervention group (insulin and metformin)/control group (insulin (and placebo)); data for continuous variables are mean (standard deviation) if reported, unless stated otherwise.

†Data only for participants who completed the trial.

$\S$ Data only reported for the total number of participants undergoing randomisation. 


\section{Table 3 | Interventions in the included trials

\begin{tabular}{|c|c|c|c|c|}
\hline \multirow[b]{2}{*}{ Trial } & \multirow{2}{*}{$\begin{array}{l}\text { Participants } \\
\text { allowed metformin } \\
\text { treatment at entry? }\end{array}$} & \multirow{2}{*}{$\begin{array}{l}\text { Insulin } \\
\text { naive } \\
\text { participants } \\
\text { at baseline }\end{array}$} & \multicolumn{2}{|c|}{$\begin{array}{l}\text { Insulin dose at baseline } \\
\text { (U/day) }\end{array}$} \\
\hline & & & Intervention & Control \\
\hline $\begin{array}{l}\text { Altuntas et al, } \\
2003^{43}\end{array}$ & $\begin{array}{l}\text { No; patients received } \\
\text { diet and sulphonylurea }\end{array}$ & Yes & - & - \\
\hline
\end{tabular} \\ No; patients received
diet and sulphonylurea \\ Yes}

(2)

\section{Trial regimen \\ Intervention \\ Control}

850 mg metformin, twice daily; insulin lispro (initial $0.3 \mathrm{U} / \mathrm{kg}$ per day, before meals)

\begin{tabular}{|c|c|c|c|c|c|c|}
\hline $\begin{array}{l}\text { Avilés-Santa et } \\
\text { al, } 1999^{48}\end{array}$ & NR & No & $96.2(44.9)$ & $96.9(43.4)$ & $\begin{array}{l}\text { Metformin, twice daily, titrated up to } \\
2000 \mathrm{mg} \text {; insulin type and regimen } \\
\text { not changed from baseline }\end{array}$ & $\begin{array}{l}\text { Placebo tablets; insulin type not } \\
\text { changed from baseline }\end{array}$ \\
\hline $\begin{array}{l}\text { Civera et al, } \\
2007^{36}\end{array}$ & $\begin{array}{l}\text { Yes; oral antidiabetic } \\
\text { drugs }\end{array}$ & Yes & - & - & $\begin{array}{l}850 \mathrm{mg} \text { metformin, twice daily; } \\
\text { neutral protamine Hagedorn insulin } \\
\text { (initial } 0.2 \mathrm{U} / \mathrm{kg} \text { per day, before } \\
\text { dinner) }\end{array}$ & $\begin{array}{l}\text { Neutral protamine Hagedorn } \\
\text { insulin (initial } 0.3 \mathrm{U} / \mathrm{kg} \text { per day; } \\
\text { two thirds before breakfast and } \\
\text { one third before dinner) }\end{array}$ \\
\hline $\begin{array}{l}\text { Douek et al, } \\
2005^{4}\end{array}$ & $\begin{array}{l}\text { Yes; oral antidiabetic } \\
\text { drugs }\end{array}$ & Yes & - & - & $\begin{array}{l}2 \mathrm{~g} \text { metformin per day, divided into } \\
\text { two doses; no management } \\
\text { protocol for insulin, insulin type } \\
\text { decided by investigator }\end{array}$ & $\begin{array}{l}\text { Placebo tablets; no management } \\
\text { protocol for insulin, insulin type } \\
\text { decided by investigator }\end{array}$ \\
\hline $\begin{array}{l}\text { Galani et al, } \\
2011^{37}\end{array}$ & $\begin{array}{l}\text { Assuming yes; routine } \\
\text { oral antidiabetic drugs }\end{array}$ & Yes & - & - & $\begin{array}{l}500 \text { mg metformin per day; insulin } \\
\text { isophane (fixed dose } 10 \mathrm{U} / \text { day) }\end{array}$ & $\begin{array}{l}\text { Insulin isophane (fixed dose } 10 \\
\text { U/day) }\end{array}$ \\
\hline $\begin{array}{l}\text { Giugliano et al, } \\
1992^{49}\end{array}$ & No & No & $90(9)$ & $88(9.4)$ & $\begin{array}{l}850 \text { mg metformin, twice daily; } \\
\text { insulin treatment as before } \\
\text { randomisation }\end{array}$ & $\begin{array}{l}\text { Placebo tablets; insulin treatment } \\
\text { as before randomisation }\end{array}$ \\
\hline $\begin{array}{l}\text { Heine et al, } \\
1995^{29,32,33}\end{array}$ & $\begin{array}{l}\text { Yes; metformin and } \\
\text { glipizide }\end{array}$ & Yes & NR & NR & $\begin{array}{l}\text { Metformin; neutral protamine } \\
\text { Hagedorn insulin (at bedtime) }\end{array}$ & $\begin{array}{l}\text { Neutral protamine Hagedorn } \\
\text { insulin (at bedtime) }\end{array}$ \\
\hline $\begin{array}{l}\text { Hermann et al, } \\
2001^{50}\end{array}$ & $\begin{array}{l}\text { No; exclusion criterion } \\
\text { was oral antidiabetic } \\
\text { treatment within past } \\
\text { six months }\end{array}$ & No & $72.3(27)$ & $68.8(21.7)$ & $\begin{array}{l}850 \mathrm{mg} \text { metformin twice daily; } \\
\text { insulin regimen unchanged from } \\
\text { baseline }\end{array}$ & $\begin{array}{l}\text { Placebo tablets; insulin regimen } \\
\text { unchanged from baseline }\end{array}$ \\
\hline $\begin{array}{l}\text { Hirsch et al, } \\
1999^{34}\end{array}$ & $\begin{array}{c}\text { No; no oral } \\
\text { antidiabetic drugs }\end{array}$ & No & NR & NR & $2.5 \mathrm{~g}$ metformin; insulin & Placebo tablets; insulin \\
\hline HOME, $2009^{6,17}$ & $\begin{array}{l}\text { Yes; metformin } \\
\text { allowed only in } \\
\text { combination with } \\
\text { insulin }\end{array}$ & No & $62(29)$ & $64(25)$ & $\begin{array}{l}850 \mathrm{mg} \text { metformin up to three times } \\
\text { per day; actrapid (before three main } \\
\text { meals) and insulatard (at bedtime); } \\
\text { alternatively, mixed insulin (before } \\
\text { breakfast and dinner) }\end{array}$ & $\begin{array}{l}\text { Placebo tablets; actrapid (before } \\
\text { three main meals) and insulatard } \\
\text { (at bedtime); alternatively, mixed } \\
\text { insulin (before breakfast and } \\
\text { dinner) }\end{array}$ \\
\hline $\begin{array}{l}\text { Kabadi et al, } \\
2006^{38}\end{array}$ & $\begin{array}{l}\text { Yes; metformin } \\
\text { monotherapy, } \\
\text { glimepiride } \\
\text { monotherapy, or } \\
\text { combination of both } \\
\text { drugs }\end{array}$ & Yes & - & - & $\begin{array}{l}2.5 \mathrm{~g} \text { metformin; biphasic insulin } \\
\text { aspart } 30 / 70 \text { (initial dose } 10 \mathrm{U} \text {, } \\
\text { before dinner) }\end{array}$ & $\begin{array}{l}\text { Placebo tablets; biphasic insulin } \\
\text { aspart } 30 / 70 \text { (initial dose } 10 \mathrm{U} \text {, } \\
\text { before dinner) }\end{array}$ \\
\hline $\begin{array}{l}\text { Kokic et al, } \\
2003^{42}\end{array}$ & $\begin{array}{l}\text { Yes; oral antidiabetic } \\
\text { drugs }\end{array}$ & Yes & - & - & $\begin{array}{l}\text { Metformin; insulin lispro (thrice } \\
\text { daily) }\end{array}$ & $\begin{array}{l}\text { Biphasic insulin 30/70 (twice } \\
\text { daily); neutral protamine Hagedorn } \\
\text { insulin (at bedtime) }\end{array}$ \\
\hline $\begin{array}{l}\text { Kokic et al, } \\
2010^{45}\end{array}$ & Assuming yes; NR & NR & - & - & $\begin{array}{l}\text { Two doses of metformin; lispro } \\
\text { insulin (before meals) }\end{array}$ & $\begin{array}{l}\text { Biphasic insulin } 30 / 70 \text { (before } \\
\text { breakfast and dinner); neutral } \\
\text { protamine Hagedorn insulin (at } \\
\text { bedtime) }\end{array}$ \\
\hline $\begin{array}{l}\text { Kvapil et al, } \\
2005^{39}\end{array}$ & $\begin{array}{l}\text { Yes; metformin } \\
\text { monotherapy }\end{array}$ & Yes & - & & $\begin{array}{l}\text { Metformin maintained at pretrial } \\
\text { dosages; biphasic insulin aspart } \\
30 / 70 \text { (initial dose } 0.2 \mathrm{U} / \mathrm{kg} \text { per day, } \\
\text { before breakfast and dinner) }\end{array}$ & $\begin{array}{l}\text { Biphasic insulin aspart 30/70 } \\
\text { (dose } 0.3 \mathrm{U} / \mathrm{kg} \text { per day, before } \\
\text { breakfast and dinner) }\end{array}$ \\
\hline $\begin{array}{l}\text { Onuchin et al, } \\
2010^{40}\end{array}$ & $\begin{array}{l}\text { Yes; oral antidiabetic } \\
\text { drugs }\end{array}$ & Yes & - & - & $\begin{array}{l}1.5-2.5 \mathrm{~g} \text { metformin per day; long } \\
\text { acting insulin (initial } 0.2-0.4 \mathrm{U} / \mathrm{kg} \\
\text { per day, two thirds before breakfast, } \\
\text { one third at bedtime) }\end{array}$ & $\begin{array}{l}\text { Long acting insulin (initial } 0.2-0.4 \\
\mathrm{U} / \mathrm{kg} \text { per day, two thirds before } \\
\text { breakfast, one third at bedtime); } \\
\text { (actrapid } 1-1.5 \mathrm{U} / 10 \mathrm{~g} \\
\text { carbohydrate, at meals) }\end{array}$ \\
\hline
\end{tabular}


Table 3 (continued)

\begin{tabular}{|c|c|c|c|c|c|c|}
\hline \multirow[b]{2}{*}{ Trial } & \multirow{2}{*}{$\begin{array}{l}\text { Participants } \\
\text { allowed metformin } \\
\text { treatment at entry? }\end{array}$} & \multirow{2}{*}{$\begin{array}{l}\text { Insulin } \\
\text { naive } \\
\text { participants } \\
\text { at baseline }\end{array}$} & \multicolumn{2}{|c|}{$\begin{array}{l}\text { Insulin dose at baseline } \\
\text { (U/day) }\end{array}$} & \multicolumn{2}{|c|}{ Trial regimen } \\
\hline & & & Intervention & Control & Intervention & Control \\
\hline $\begin{array}{l}\text { Ponssen et al, } \\
2000^{35}\end{array}$ & $\begin{array}{c}\text { Yes; oral antidiabetic } \\
\text { drugs }\end{array}$ & No & $12(0-96)^{*} \dagger$ & $12(0-96)^{*} \dagger$ & $\begin{array}{l}\text { Metformin; mixed insulin 30/70 } \\
\text { (twice daily) }\end{array}$ & $\begin{array}{l}\text { Placebo tablets; mixed insulin } \\
30 / 70 \text { (twice daily) }\end{array}$ \\
\hline $\begin{array}{l}\text { Relimpio et al, } \\
1998^{18}\end{array}$ & NR & No & $47.9(10)$ & $51.8(9.6)$ & $\begin{array}{l}\text { Metformin, titrated up to } 2550 \\
\text { mg/day, after four weeks; insulin } \\
\text { regimen maintained }\end{array}$ & $\begin{array}{l}10 \% \text { increase in insulin from } \\
\text { baseline }\end{array}$ \\
\hline $\begin{array}{l}\text { Robinson et al, } \\
1998, \text { study } 1^{30}\end{array}$ & $\begin{array}{c}\text { No; no oral } \\
\text { antidiabetic drugs }\end{array}$ & No & $71(47)^{*}$ & $71(47)^{*}$ & $1 \mathrm{~g}$ metformin twice a daily; insulin & Placebo tablets; insulin \\
\hline $\begin{array}{l}\text { Robinson et al, } \\
1998, \text { study } 2^{30}\end{array}$ & $\begin{array}{l}\text { Yes; metformin in } \\
\text { combination with } \\
\text { insulin }\end{array}$ & No & $41(16) \dagger$ & $41(16) \dagger$ & $1 \mathrm{~g}$ metformin twice a daily; insulin & Placebo tablets; insulin \\
\hline $\begin{array}{l}\text { Schnack et al, } \\
1996^{31}\end{array}$ & $\begin{array}{c}\text { No; sulphonylurea } \\
\text { monotherapy }\end{array}$ & Yes & - & - & $\begin{array}{l}\text { Metformin; mixed insulin (twice } \\
\text { daily) }\end{array}$ & Mixed insulin (twice daily) \\
\hline SDDSa, $2011^{44,65}$ & $\begin{array}{c}\text { Yes; oral antidiabetic } \\
\text { drugs }\end{array}$ & No & NR & NR & $\begin{array}{l}\text { Metformin, titrated to } 2000 \mathrm{mg} / \text { day, } \\
\text { in four weeks; neutral protamine } \\
\text { Hagedorn insulin (naive use, initial } \\
\text { dose } 12 \mathrm{U} / \text { day; previous use, half } \\
\text { previous daily dose) }\end{array}$ & $\begin{array}{l}\text { Placebo tablets; neutral protamine } \\
\text { Hagedorn insulin (naive use, initial } \\
\text { dose } 12 \text { U/day; previous use, half } \\
\text { previous daily dose) }\end{array}$ \\
\hline SDDSb, $2011^{44,65}$ & $\begin{array}{l}\text { Yes; oral antidiabetic } \\
\text { drugs }\end{array}$ & No & NR & NR & $\begin{array}{l}\text { Metformin, titrated to } 2000 \mathrm{mg} / \mathrm{day} \text {, } \\
\text { in four weeks; insulin aspart (naïve } \\
\text { use, initial dose } 4 \mathrm{U} \text { before each } \\
\text { main meal; previous use: initial } \\
\text { dose } 50 \% \text { of previous daily dose } \\
\text { divided in three, before each main } \\
\text { meal) }\end{array}$ & $\begin{array}{l}\text { Placebo tablets; insulin aspart } \\
\text { (naïve use, initial dose } 4 U \text { before } \\
\text { each main meal; previous use: } \\
\text { initial dose } 50 \% \text { of previous daily } \\
\text { dose divided in three, before each } \\
\text { main meal) }\end{array}$ \\
\hline $\begin{array}{l}\text { Strowig et al, } \\
2002^{47}\end{array}$ & $\begin{array}{l}\text { No; no oral } \\
\text { antidiabetic drugs }\end{array}$ & No & $82.9(48.2)$ & $80.3(41.7)$ & $\begin{array}{l}\text { Metformin, titrated to } 2000 \mathrm{mg} / \mathrm{day} \text {, } \\
\text { in four weeks; insulin dose not } \\
\text { increased, but dose decreased if } \\
\text { frequent hypoglycaemia occurred }\end{array}$ & $\begin{array}{l}\text { Insulin dose increased to achieve } \\
\text { normal levels of glycaemia }\end{array}$ \\
\hline $\begin{array}{l}\text { Ushakova et al, } \\
2007^{41}\end{array}$ & $\begin{array}{l}\text { Yes; oral antidiabetic } \\
\text { drugs }\end{array}$ & Yes & - & - & $\begin{array}{l}\text { Metformin, titrated to } 2000 \mathrm{mg} / \text { day; } \\
\text { biphasic insulin aspart } 30 / 70 \text { (initial } \\
\text { dose } 0.3-0.5 \mathrm{U} / \mathrm{kg} \text { per day, before } \\
\text { breakfast and dinner) }\end{array}$ & $\begin{array}{l}\text { Biphasic insulin aspart } 30 / 70 \\
\text { (initial dose } 0.3-0.5 \mathrm{U} / \mathrm{kg} \text { per day, } \\
\text { before breakfast and dinner) }\end{array}$ \\
\hline $\begin{array}{l}\text { Vähätalo et al, } \\
2007^{46}\end{array}$ & $\begin{array}{l}\text { Yes; oral antidiabetic } \\
\text { drugs }\end{array}$ & No & 21.1 & 42.7 & $\begin{array}{l}\text { Metformin, titrated to } 2500 \mathrm{mg} / \mathrm{day} \text {; } \\
\text { neutral protamine Hagedorn insulin } \\
\text { (at bedtime) or Lente insulin (at } \\
\text { bedtime) }\end{array}$ & $\begin{array}{l}\text { Neutral protamine Hagedorn } \\
\text { insulin (in the morning and at } \\
\text { bedtime) }\end{array}$ \\
\hline $\begin{array}{l}\text { Yilmaz et al, } \\
2007^{51}\end{array}$ & $\begin{array}{l}\text { No; no oral } \\
\text { antidiabetic drugs }\end{array}$ & No & $52.2(13.6)$ & $42.7(14.3)$ & $\begin{array}{l}1700 \text { mg metformin per day; } \\
\text { biphasic insulin aspart 30/70 twice } \\
\text { daily }\end{array}$ & $\begin{array}{l}\text { Biphasic insulin aspart 30/70 twice } \\
\text { daily }\end{array}$ \\
\hline $\begin{array}{l}\text { Yki-Järvinen et } \\
\text { al, } 1999^{3,66}\end{array}$ & $\begin{array}{l}\text { No; inclusion criterion } \\
\text { was previous } \\
\text { treatment with } \\
\text { glipizide or glyburide }\end{array}$ & Yes & - & - & $\begin{array}{l}2000 \text { mg metformin divided in two } \\
\text { doses; neutral human isophane } \\
\text { (initial dose same as fasting blood } \\
\text { glucose levels ( } \mathrm{mmol} / \mathrm{L} \text { ), before } \\
\text { bedtime) }\end{array}$ & $\begin{array}{l}\text { Neutral human isophane (initial } \\
\text { dose same as fasting blood } \\
\text { glucose levels (mmol/L), before } \\
\text { bedtime); second injection of } \\
\text { neutral human isophane insulin } \\
\text { (before breakfast) }\end{array}$ \\
\hline
\end{tabular}

NR=not reported; SDDS=South Danish Diabetes Study; SDDSa=intervention group in the South Danish Diabetes Study prescribed neutral protamine Hagedorn insulin in combination with metformin or placebo; SDDSb=intervention group in the South Danish Diabetes Study prescribed insulin aspart in combination with metformin or placebo; Robinson study 1 =participants were exclusively treated with insulin at entry to trial and randomised to metformin or placebo in addition to insulin; Robinson study 2=participants received combination of metformin and insulin at entry to the trial, but after entry to the trial participants were randomised to receive either metformin or placebo; intervention=group receiving insulin and metformin; control=group receiving insulin (and placebo). Data for continuous variables are mean (standard deviation) if reported, unless stated otherwise.

*Interquartile range.

†Number only reported for both intervention groups together. 


\begin{tabular}{|c|c|c|c|c|c|c|c|c|}
\hline Trial & $\begin{array}{l}\text { Sequence } \\
\text { generation }\end{array}$ & $\begin{array}{l}\text { Allocation } \\
\text { concealment }\end{array}$ & $\begin{array}{l}\text { Blinding of } \\
\text { participants and } \\
\text { investigators }\end{array}$ & $\begin{array}{l}\text { Blinding of } \\
\text { outcome } \\
\text { assessors }\end{array}$ & $\begin{array}{l}\text { Complete } \\
\text { outcome data }\end{array}$ & $\begin{array}{l}\text { Selective } \\
\text { outcome } \\
\text { reporting }\end{array}$ & Academic bias & Sponsor bias \\
\hline Altuntas et al, $2003^{43}$ & Unclear & Unclear & Inadequate & Inadequate & Unclear & Unclear & Adequate & Unclear \\
\hline $\begin{array}{l}\text { Avilés-Santa et al, } \\
1999^{48}\end{array}$ & Unclear & Unclear & Adequate & Adequate & Adequate & Unclear & Adequate & Inadequate \\
\hline Civera et al, $2007^{36}$ & Unclear & Unclear & Inadequate & Inadequate & Adequate & Unclear & Adequate & Unclear \\
\hline Douek et al, $2005^{4}$ & Unclear & Unclear & Adequate & Adequate & Adequate & Unclear & Adequate & Inadequate \\
\hline Galani et al, $2011^{37}$ & Unclear & Unclear & Inadequate & Inadequate & Unclear & Unclear & Adequate & Unclear \\
\hline Giugliano et al, $1992^{49}$ & Unclear & Unclear & Unclear & Unclear & Unclear & Unclear & Adequate & Unclear \\
\hline Heine et al, $1995^{29,32,33}$ & Unclear & Unclear & Inadequate & Inadequate & Unclear & Unclear & Adequate & Inadequate \\
\hline Hermann et al, $2001^{50}$ & Unclear & Unclear & Adequate & Adequate & Adequate & Unclear & Adequate & Unclear \\
\hline Hirsch et al, $1999^{34}$ & Unclear & Unclear & Unclear & Unclear & Adequate & Unclear & Adequate & Unclear \\
\hline HOME, $2009^{6,17}$ & Adequate & Adequate & Adequate & Adequate & Adequate & Adequate & Adequate & Inadequate \\
\hline Kabadi et al, $2006^{38}$ & Adequate & Adequate & Inadequate & Inadequate & Adequate & Unclear & Inadequate & Unclear \\
\hline Kokic et al, $2003^{42}$ & Unclear & Unclear & Inadequate & Inadequate & Unclear & Unclear & Inadequate & Unclear \\
\hline Kokic et al, $2010^{45}$ & Unclear & Unclear & Inadequate & Inadequate & Unclear & Unclear & Adequate & Unclear \\
\hline Kvapil et al, $2005^{39}$ & Adequate & Adequate & Inadequate & Inadequate & Adequate & Unclear & Adequate & Inadequate \\
\hline Onuchin et al, $2010^{40}$ & Unclear & Unclear & Inadequate & Inadequate & Unclear & Unclear & Adequate & Unclear \\
\hline Ponssen et al, $2000^{35}$ & Unclear & Unclear & Unclear & Unclear & Adequate & Unclear & Adequate & Inadequate \\
\hline Relimpio et al, $1998^{18}$ & Unclear & Unclear & Inadequate & Inadequate & Adequate & Unclear & Adequate & Inadequate \\
\hline $\begin{array}{l}\text { Robinson et al, 1998, } \\
\text { study } 1^{30}\end{array}$ & Unclear & Unclear & Unclear & Unclear & Adequate & Unclear & Adequate & Inadequate \\
\hline $\begin{array}{l}\text { Robinson et al, 1998, } \\
\text { study } 2^{30}\end{array}$ & Unclear & Unclear & Unclear & Unclear & Adequate & Unclear & Adequate & Inadequate \\
\hline Schnack et al, $1996^{31}$ & Unclear & Unclear & Inadequate & Inadequate & Unclear & Unclear & Adequate & Inadequate \\
\hline SDDS, $2011^{44,65}$ & Adequate & Adequate & Adequate & Adequate & Adequate & Adequate & Adequate & Inadequate \\
\hline Strowig et al, $2002^{47}$ & Adequate & Adequate & Inadequate & Inadequate & Adequate & Unclear & Adequate & Inadequate \\
\hline Ushakova et al, $2007^{41}$ & Unclear & Adequate & Inadequate & Inadequate & Adequate & Unclear & Adequate & Inadequate \\
\hline Vähätalo et al, $2007^{46}$ & Unclear & Unclear & Inadequate & Inadequate & Unclear & Unclear & Adequate & Unclear \\
\hline Yilmaz et al, $2007^{51}$ & Unclear & Unclear & Inadequate & Inadequate & Adequate & Unclear & Adequate & Unclear \\
\hline $\begin{array}{l}\text { Yki-Järvinen et al, } \\
1999^{3,66}\end{array}$ & Unclear & Unclear & Inadequate & Inadequate & Adequate & Unclear & Adequate & Inadequate \\
\hline
\end{tabular}

SDDS=South Danish Diabetes Study; Robinson study 1=participants were exclusively treated with insulin at entry to trial and randomised to metformin or placebo in addition to insulin; Robinson study $2=$ participants received combination of metformin and insulin at entry to the trial, but after entry to the trial participants were randomised to receive either metformin or placebo. 


\section{Figures}

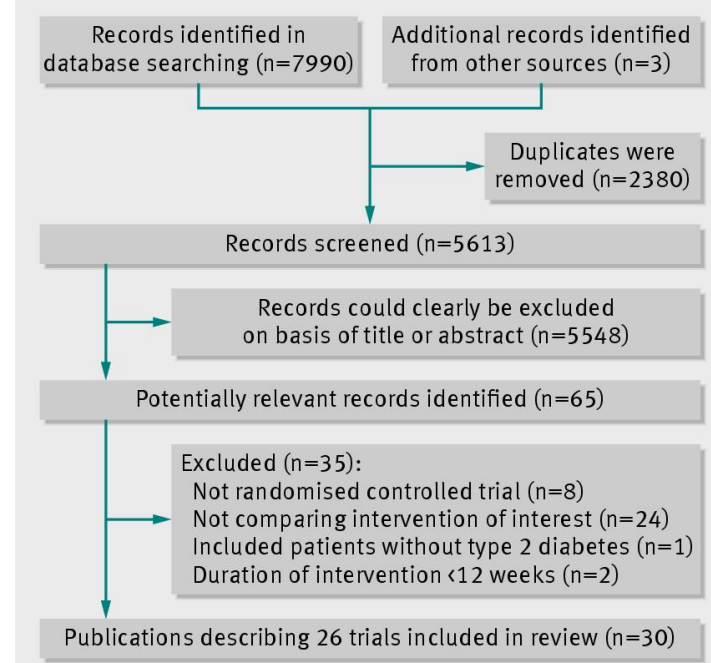

Fig 1 Identification of trials for inclusion 


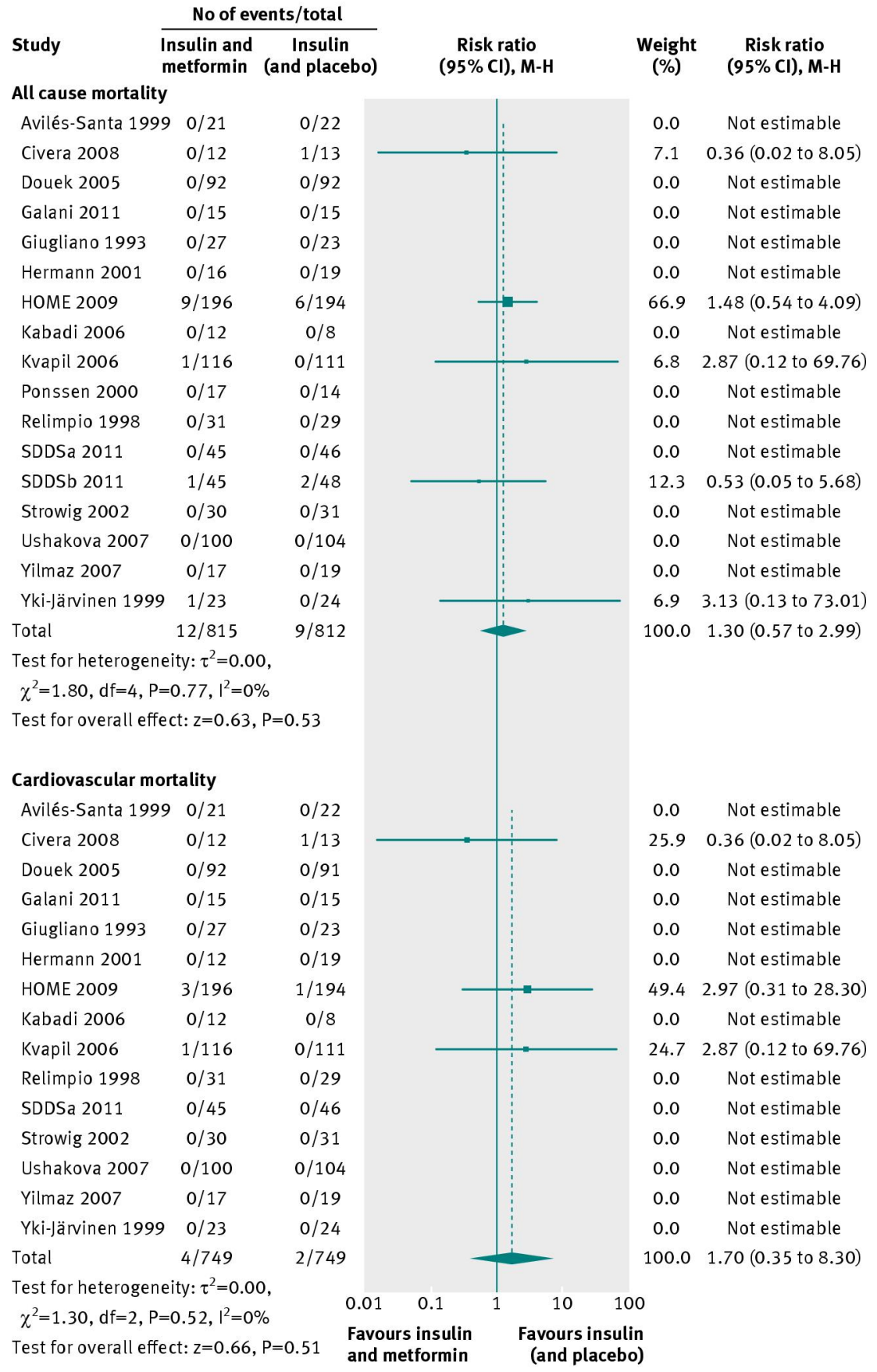

Fig 2 Forest plots for trial outcomes in all cause mortality and cardiovascular mortality. $\mathrm{M}-\mathrm{H}=\mathrm{Mantel}-\mathrm{Haenszel} ; \mathrm{Cl}=\mathrm{confidence}$ interval. Random effects model used. 


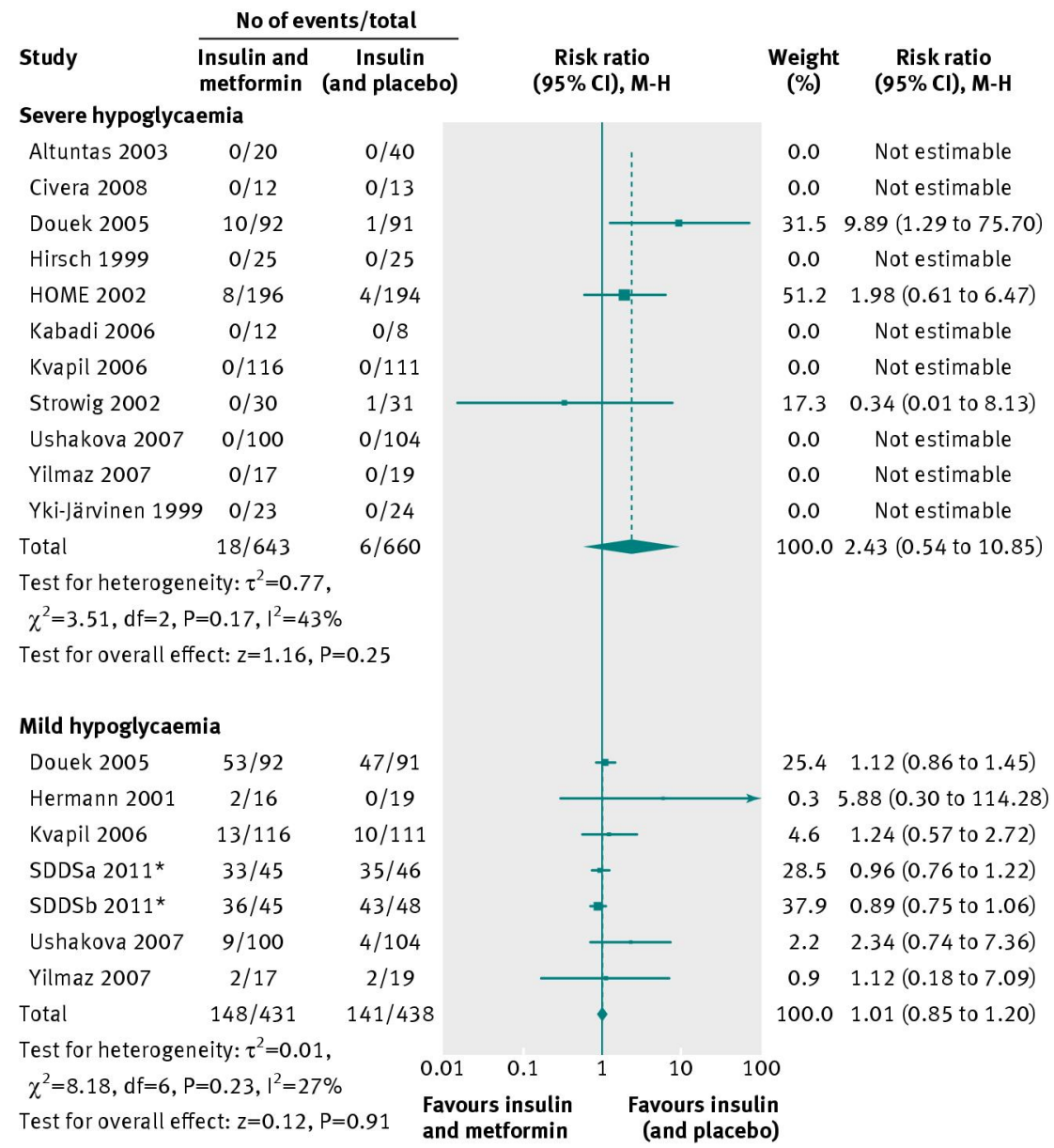

Fig 3 Forest plots for trial outcomes in severe hypoglycaemia and mild hypoglycaemia. $\mathrm{M}-\mathrm{H}=\mathrm{Mantel}-\mathrm{Haenszel} ; \mathrm{Cl}=\mathrm{confidence}$ interval. Random effects model used. *Trial only reported hypoglycaemia and did not specify severity

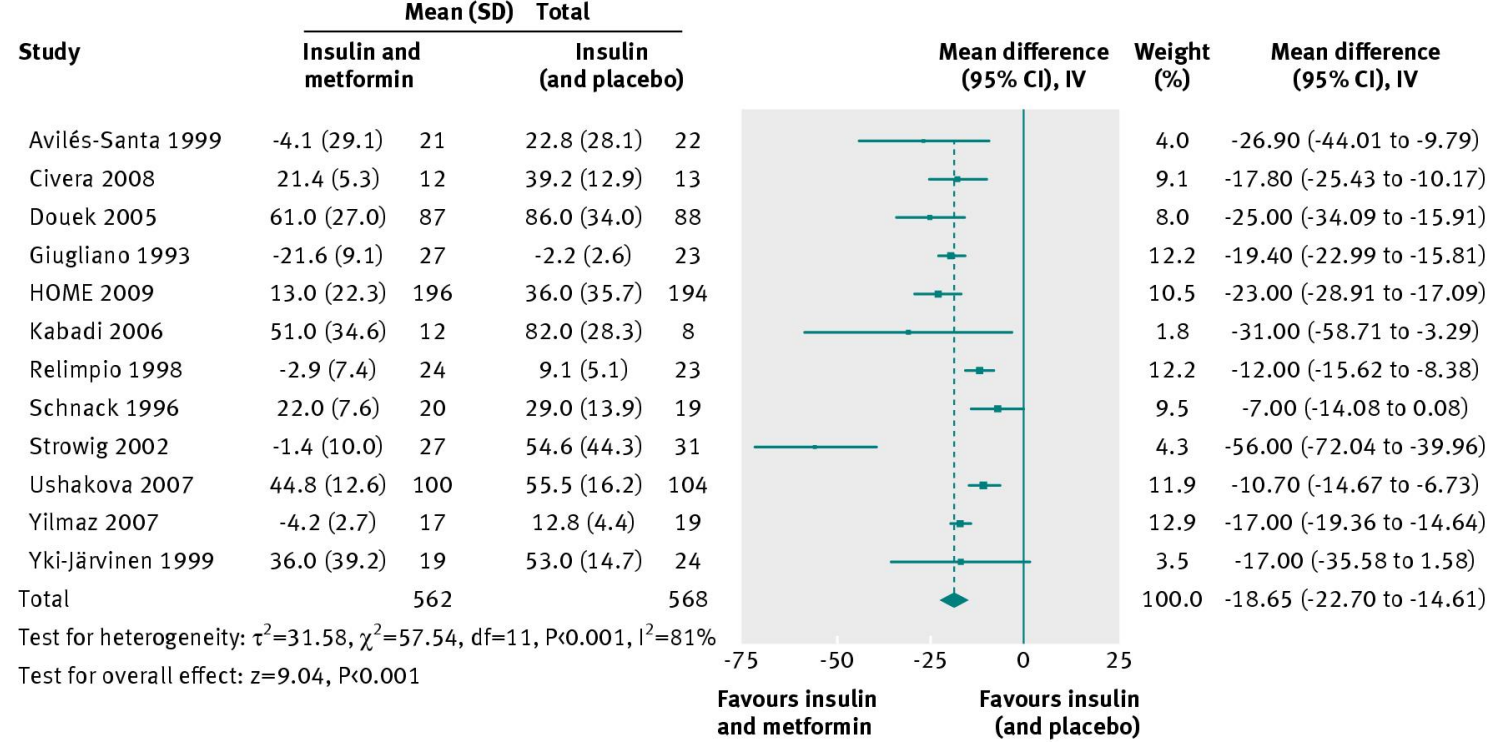

Fig 4 Forest plot for changes in insulin dose (U/day) from baseline to end of follow-up. IV=inverse variance; $\mathrm{Cl}=\mathrm{confidence}$ interval. Random effects model used 

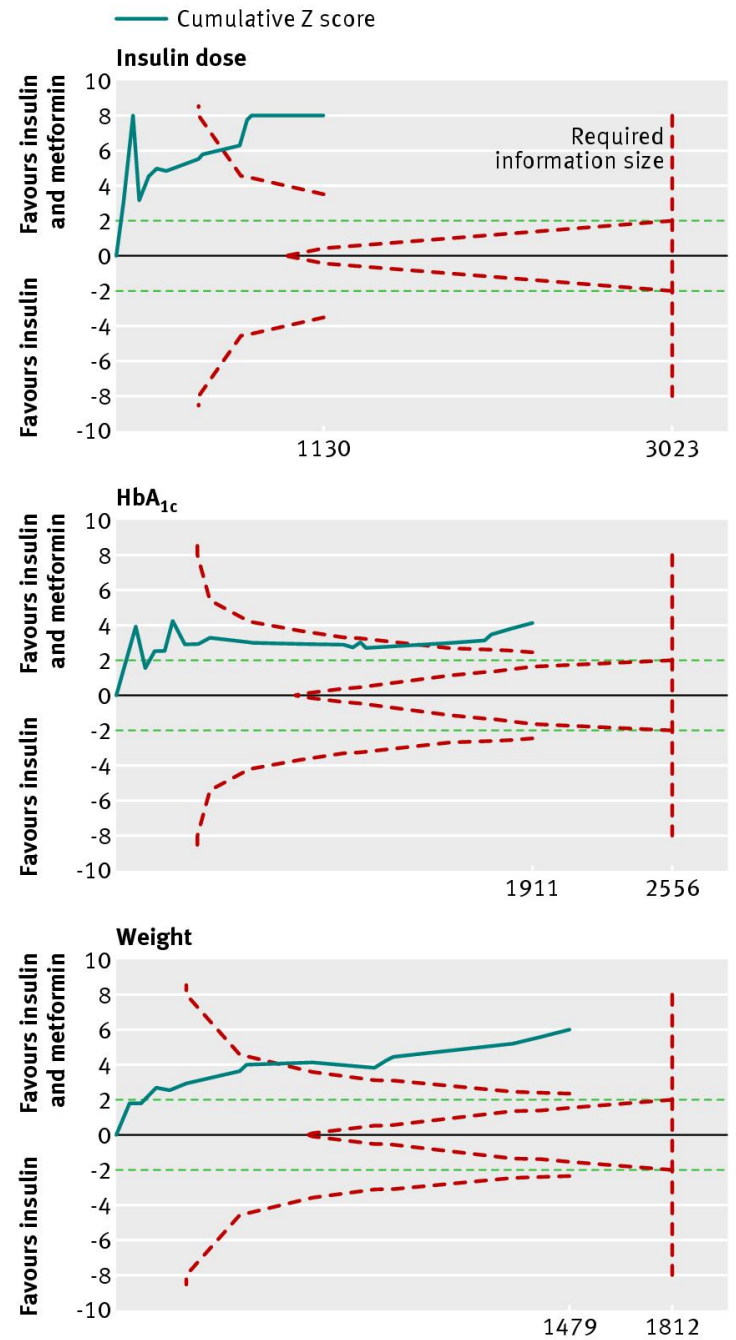

No of patients (linear scale)

Fig 5 Trial sequential analysis of effect of metformin and insulin versus insulin alone in type 2 diabetes on insulin dose, $\mathrm{HbA}_{1 \mathrm{c}}$, and weight. The required information size (and adjacent trial sequential alpha spending monitoring boundaries) for insulin dose was calculated based on a two sided $\alpha=5 \%$; power of $80 \%$; a minimal relevant difference of $-5 \mathrm{U} / \mathrm{day}$; a standard deviation of $17.6 \mathrm{U} /$ day; and a diversity of $87 \%$ as estimated in a random effects model. The required information size (and the adjacent trial sequential alpha spending monitoring boundaries) for $\mathrm{HbA}_{1 \mathrm{c}}$ was calculated based on a two sided $\mathrm{a}=5 \%$; power of $80 \%$; a minimal relevant difference of $-0.5 \%$; a standard deviation of $1.6 \%$; and a diversity of $80 \%$ as estimated in a random effects model. The required information size (and the adjacent trial sequential alpha spending monitoring boundaries) for weight was calculated based on a two sided $a=5 \%$; power of $80 \%$; a minimal relevant difference of $-1 \mathrm{~kg}$; a standard deviation of $7.96 \mathrm{~kg}$; and a diversity of $48 \%$ as estimated in a random effects model. The solid blue cumulative $Z$ curves indicate the cumulated $Z$ score from the inverse variance model $Z$ statistic, whenever a new trial is added. The solid blue cumulative $Z$ curves all cross the dashed red trial sequential alpha spending monitoring boundaries. Horizontal dotted green lines illustrate traditional level of statistical significance $(P=0.05)$ 
Study

$\begin{array}{lcccc}\text { Altuntas 2003 } & -2.7(4.4) & 20 & -2.4(5.2) & 40 \\ \text { Avilés-Santa 1999 } & -2.5(2.3) & 21 & -1.6(1.2) & 22 \\ \text { Civera 2008 } & -0.7(1.2) & 12 & -1.4(1.6) & 13 \\ \text { Douek 2005 } & -1.5(1.1) & 87 & -1.3(1.0) & 88 \\ \text { Galani 2011 } & -3.8(0.6) & 15 & -2.3(0.5) & 15 \\ \text { Giugliano 1993 } & -1.9(1.2) & 27 & -0.2(0.8) & 23 \\ \text { Hermann 2001 } & -1.1(0.4) & 16 & 0.3(0.6) & 19 \\ \text { Hirsch 1999 } & -1.2(1.8) & 22 & -0.8(2.2) & 25 \\ \text { HOME 2009 } & -0.2(1.0) & 196 & 0.0(0.8) & 194 \\ \text { Kabadi 2006 } & -2.5(4.0) & 12 & -2.8(2.9) & 8 \\ \text { Kokic 2003 } & -2.0(1.7) & 29 & -1.2(1.3) & 29 \\ \text { Kokic 2010 } & -2.6(1.6) & 79 & -2.2(1.5) & 79 \\ \text { Kvapil 2006 } & -1.7(3.6) & 108 & -1.6(4.0) & 107 \\ \text { Relimpio 1998 } & -1.9(2.2) & 24 & 0.03(1.7) & 23 \\ \text { Schnack 1996 } & -1.6(1.8) & 20 & -1.7(1.3) & 19 \\ \text { SDDSa 2011 } & -1.3(1.1) & 45 & -0.4(1.0) & 46 \\ \text { SDSSb 2011 } & -1.2(1.02) & 45 & -0.6(0.8) & 48 \\ \text { Strowig 2002 } & -1.7(1.0) & 27 & -1.7(1.1) & 31 \\ \text { Ushakowa 2007 } & -3.0(1.6) & 100 & -2.9(1.5) & 104 \\ \text { Vähätalo 2007 } & -1.5(1.2) & 26 & -1.8(2.1) & 11 \\ \text { Yilmaz 2007 } & -2.0(1.0) & 17 & -1.2(1.1) & 19 \\ \text { Total } & & 948 & & 963 \\ \text { Test for heterogeneity: } \tau^{2}=0.29, \chi^{2}=110.65, \mathrm{df}=20, \mathrm{P}<0.001, \mathrm{I}^{2}=82 \% \\ \text { Test for 0verall effect: Z=4.11, P<0.001 } & & \end{array}$

Test for overall effect: $z=4.11, P<0.001$

(and placebo)

\section{Mean (SD) Total}

Insulin and Insulin

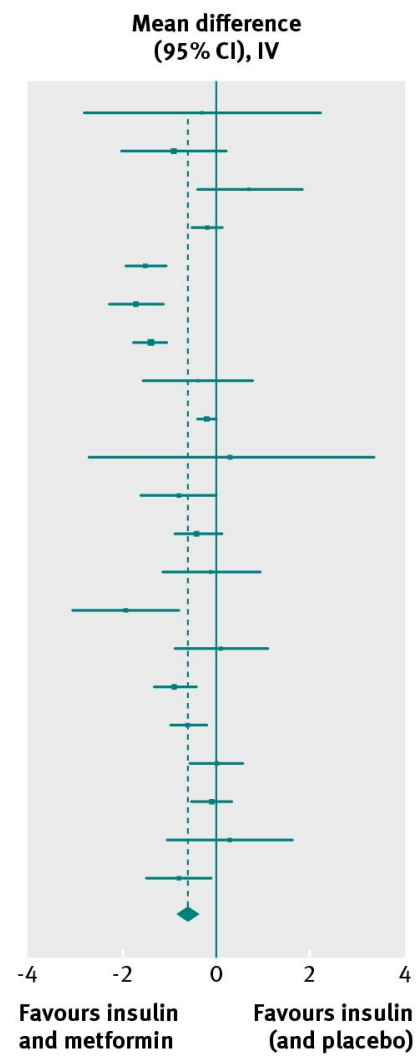

Weight Mean difference

(\%) $\quad(95 \% \mathrm{Cl})$, IV

$1.1-0.30(-2.81$ to 2.21$)$

$3.5-0.90(-2.00$ to 0.20$)$

$3.5 \quad 0.70(-0.40$ to 1.80$)$

$6.8-0.20(-0.51$ to 0.11$)$

$6.4-1.50(-1.90$ to -1.10$)$

$5.7-1.70(-2.26$ to -1.14$)$

$6.7-1.40(-1.73$ to -1.07$)$

$3.4-0.40(-1.54$ to 0.74$)$

$7.1-0.20(-0.38$ to -0.02$)$

$0.8 \quad 0.30(-2.73$ to 3.33$)$

$4.8 \quad-0.80(-1.58$ to -0.02$)$

$6.1-0.40(-0.88$ to 0.08$)$

$3.8-0.10(-1.12$ to 0.92$)$

$3.4-1.93(-3.05$ to -0.81$)$

$3.9 \quad 0.10$ (-0.88 to 1.08$)$

$6.3-0.90(-1.33$ to -0.47$)$

$6.5-0.60(-0.97$ to -0.23$)$

$5.8 \quad 0.00(-0.54$ to 0.54$)$

$6.3-0.10(-0.53$ to 0.33$)$

$2.9 \quad 0.30(-1.02$ to 1.62$)$

$5.2-0.80(-1.49$ to -0.11$)$

$100.0-0.60(-0.89$ to -0.31$)$

Fig 6 Forest plot for changes in $\mathrm{HbA}_{1 \mathrm{c}}(\%)$ from baseline to end of follow-up. IV=inverse variance; $\mathrm{Cl}=$ confidence interval. Random effects model used

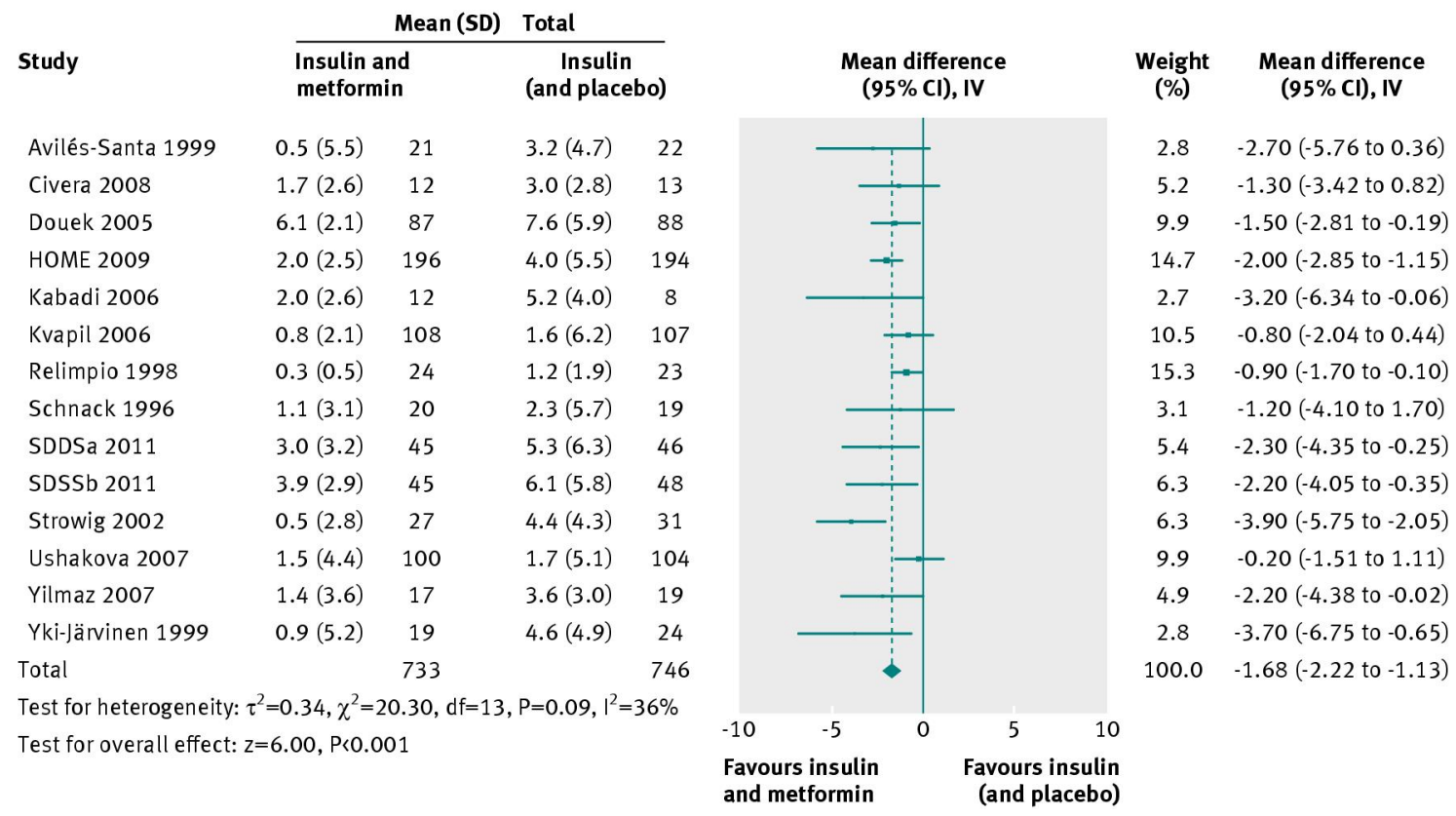

Fig 7 Forest plot for changes in weight $(\mathrm{kg})$ from baseline to end of follow-up. IV=inverse variance; $\mathrm{Cl}=\mathrm{confidence}$ interval. Random effects model used 